\title{
Computed tomography analysis of guinea pig bone: Architecture, bone thickness and dimensions throughout development
}

The domestic guinea pig, Cavia aperea f. porcellus, belongs to the Caviidae family of rodents. It is an important species as a pet, a source of food and in medical research. Adult weight is achieved at 8-12 months and life expectancy is 5-6 years. Our aim was to map bone local thickness, structure and dimensions across developmental stages in the normal animal. Guinea pigs $(n=23)$ that had died of natural causes were collected and the bones manually extracted and cleaned. Institutional ethical permission was given under the UK Home Office guidelines and the Veterinary Surgeons Act. X-ray Micro Computed Tomography (microCT) was undertaken on the left and right scapula, humerus and femur from each animal to ascertain bone local thickness. Images were also used to undertake manual and automated bone measurements, volumes and surface areas, identify and describe nutrient, supratrochlear and supracondylar foramina. Statistical analysis between groups was carried out using ANOVA with post-hoc testing. Our data mapped a number of dimensions, and mean and maximum bone thickness of the scapula, humerus and femur in guinea pigs aged 0-1 month, 1-3 months, 3-6 months, 6 months -1 year and 1-4 years. Bone dimensions, growth rates and local bone thicknesses differed between ages and between the scapula, humerus and femur. The microCT and imaging software technology showed very distinct differences between the relative local bone thickness across the structure of the bones. Only one bone showed a singular nutrient foramen, every other bone had between 2 and 5 , and every nutrient canal ran in an oblique direction. In contrast to other species, a supratrochlear foramen was observed in every humerus whereas the supracondylar foramen was always absent. Our data showed the bone local thickness, bone structure and measurements of 
guinea pig bones from birth to 4 years old. Importantly it showed that bone development continued after 1 year, the point at which most guinea pigs have reached full weight. This study is the first to show the high abundance (100\% in this study) of the supratrochlear foramen within the guinea pig humerus and the complete absence of a supracondylar foramen which is different to many other species and may also affect potential fracture points and frequencies. Understanding bone morphology and growth is essential in not only understanding the requirements of the healthy guinea pig, but also necessary in order to investigate disease states. 
1 Computed Tomography Analysis of Guinea Pig Bone: Architecture, Bone Thickness and

2 Dimensions throughout Development

3 Agata Witkowska ${ }^{1}$, Aziza Alibhai ${ }^{1}$, Chloe Hughes ${ }^{1}$, Jennifer Price ${ }^{1}$, Karl Klisch ${ }^{1}$, Craig J.

4 Sturrock $^{2}$ and Catrin S. Rutland ${ }^{1 *}$.

5 School of Veterinary Medicine and Science ${ }^{1}$ and School of Biosciences ${ }^{2}$, University of

6 Nottingham, Sutton Bonington Campus, Sutton Bonington, Leicestershire, LE12 5RD, UK.

$7 *$ Corresponding author

8 Catrin. S. Rutland. School of Veterinary Medicine and Science, University of Nottingham, Sutton

9 Bonington Campus, Sutton Bonington, Leicestershire, LE12 5RD, UK. 01159516573.

10 Catrin.rutland@nottingham.ac.uk.

11 Keywords: Micro computed tomography, guinea pig, bone, development, anatomy. 


\section{Abstract}

13 The domestic guinea pig, Cavia aperea f. porcellus, belongs to the Caviidae family of rodents. It 14 is an important species as a pet, a source of food and in medical research. Adult weight is 15 achieved at 8-12 months and life expectancy is 5-6 years. Our aim was to map bone local 16 thickness, structure and dimensions across developmental stages in the normal animal. Guinea 17 pigs $(n=23)$ that had died of natural causes were collected and the bones manually extracted and 18 cleaned. Institutional ethical permission was given under the UK Home Office guidelines and the 19 Veterinary Surgeons Act. X-ray Micro Computed Tomography (microCT) was undertaken on the 20 left and right scapula, humerus and femur from each animal to ascertain bone local thickness. 21 Images were also used to undertake manual and automated bone measurements, volumes and 22 surface areas, identify and describe nutrient, supratrochlear and supracondylar foramina. 23 Statistical analysis between groups was carried out using ANOVA with post-hoc testing. Our 24 data mapped a number of dimensions, and mean and maximum bone thickness of the scapula, 25 humerus and femur in guinea pigs aged 0-1 month, 1-3 months, 3-6 months, 6 months- 1 year and 26 1-4 years. Bone dimensions, growth rates and local bone thicknesses differed between ages and 27 between the scapula, humerus and femur. The microCT and imaging software technology showed 28 very distinct differences between the relative local bone thickness across the structure of the 29 bones. Only one bone showed a singular nutrient foramen, every other bone had between 2 and 5, 30 and every nutrient canal ran in an oblique direction. In contrast to other species, a supratrochlear 31 foramen was observed in every humerus whereas the supracondylar foramen was always absent. 32 Our data is the first to show the bone local thickness, bone structure and measurements of guinea 33 pig bones from birth to 4 years old. Importantly it showed that bone development continued after 341 year, the point at which most guinea pigs have reached full weight. This study is the first to 35 show the high abundance (100\% in this study) of the supratrochlear foramen within the guinea 36 pig humerus and the complete absence of a supracondylar foramen, which is different to many 37 other species and may also affect potential fracture points and frequencies. Understanding bone 38 morphology and growth is essential in not only understanding the requirements of the healthy 39 guinea pig, but also necessary in order to investigate disease states. 
Introduction

41 The domestic guinea pig (Cavia aperea f. porcellus) belongs to the Caviidae family of rodents

42 (Burnie 2008) that includes subfamilies covering species closely related to guinea pigs such as

43 the Patagonian cavy, also known as the Mara (Dolichotis patagonum) or the world's largest

44 rodent, the capybara (Hydrochaerus hydrochaeris)(Burnie 2008). The guinea pig has been kept

45 as an important source of food, and is still eaten in many parts of South America, Asia and Africa

46 (Meredith \& Redrobe 2010; Morales 1995; NRC 1991). Peru alone has around 20 million guinea

47 pigs, providing around 17 thousand tonnes of meat per annum, just 4,000 tonnes less than their

48 sheep meat production (NRC 1991). The meat can fetch higher prices than pork or beef on small

49 mountain farms in such regions as Ecuador (NRC 1991). It has a relatively high protein and low

50 fat content in comparison to other alternatives such as chicken, which makes it a good nutritional

51 enrichment for many lower socio-economic families (Numbela \& Valencia 2003).

52

53 Guinea pigs are commonly kept as pets, as well as used extensively in medical research playing a

54 pivotal role in epidemiological study and pharmaceutical development (Terril \& Clemons 1997).

55 The population of guinea pigs used in research has declined from 2.5 million in the 1960's to just

56 over 200,000 in 2010 (Gad 2013; USDA 2011), but the popularity of the guinea pig as a pet has

57 soared. The number of guinea pigs kept as pets in the UK has consistently been estimated at

58 between 0.5 and 1 million since 2009 , with the guinea pig presently listed as the UK's $8^{\text {th }}$ most

59 popular pet and highest ranking rodent (PFMA 2013).

60 Adults can achieve their full weight of up to 1800 grams but more usually between 900-1200

61 grams for boars and 700-1100 grams for sows (Behrend 2008; Meredith \& Redrobe 2010) at 8-12

62 months, a higher weight than that of wild guinea pigs (Hubrecht \& Kirkwood 2010), however

63 these values vary greatly across the literature and can only be used as a rough guide. As a

64 hystricomorph, the guinea pig sow has a characteristically long gestation period of 59 to 72 days,

65 approximately double that of the rabbit (Meredith \& Redrobe 2010). Litter size varies from 2 to

66 6, with an average of three or four pups, each weighing between 40 and 120 grams (Terril \&

67 Clemons 1997). The precocial pups are born mobile, fully-furred, with their eyes open and teeth

68 present, and are therefore able to consume solid food within a few hours, although still suckle for

69 two to three weeks (Hubrecht \& Kirkwood 2010; Meredith \& Redrobe 2010). Although there is

70 wide variability across the literature, it is believed that puberty is reached at around six weeks in

71 sows and between 9-10 weeks in boars (Harkness et al. 2010). Life expectancy is generally 
72 considered to be between around 5-6 years (Mitchell \& Tully 2009), although life expectancies of

73 up to eight years are reported $(\mathrm{Gad} 2013)$.

74 Amongst their many other functions such as mineral storage or bone marrow production, bones

75 are the main levers in mammalian bodies (Bilezikian et al. 2008) enabling the animal to move.

76 Bones have an additional secondary role in homeostasis as a store of calcium and phosphorus.

77 The bone is first formed as cartilage and becomes mineralised during the final stages of

78 pregnancy, a process that continues through to puberty and beyond, suggesting that the skeleton

79 of an older animal is able to withstand higher forces than that of a neonate (Sjaastad et al. 2010).

80 The bone consistency changes constantly throughout life as it undergoes remodelling in response

81 to physical and metabolic factors which can affect density as well as volume (Frost 1997;

82 Sjaastad et al. 2010).

83 Despite the significance of the guinea pig within the food and pet industry there has been little

84 research into the normal bone structure and density/thickness. One method that enables analysis

85 of bone characteristics is Computed Tomography (CT). Since its invention in the 1970's

86 (Hounsfield 1973), CT is now widespread in clinical imaging, permitting non-destructive and

87 non-invasive quantitative measurements of the body of both humans and animals. The imaging

88 technique is based on the attenuation of $\mathrm{x}$-rays as they penetrate the material of interest at a

89 known number of angular positions. Subsequently, tomographic reconstruction algorithms are

90 used to generate a three dimensional spatial map of $\mathrm{x}$-ray attenuation of a material which can then

91 be analysed in detail using computer software (Ritman 2011). Within the last 10 years, microCT

92 systems have become more common for non-clinical applications and offer higher spatial

93 resolution, detail detectability and contrast compared to conventional CT (Metscher 2009). The

94 technique has been successfully applied to the investigation of bone development and anatomy in

95 a range of small animals including the guinea pig, mouse and rat (Bialek et al. 2014; Tao et al.

96 2014; Uzun et al. 2007; Willett et al. 2012).

97 Long bones are composed of an outer layer of dense compact bone and an inner meshwork of

98 trabecular bone, which is particularly abundant in the epiphyses, and bone marrow (Zoetis et al.

99 2003).. In comparison, flat bones, such as the scapula, consist of two thick layers of compact

100 bone with a layer of trabecular bone in between. The blade of the scapula is said to undergo

101 intramembranous ossification, in which the bone develops from a fibrous membrane, whereas 
102 some of the outer parts undergo endochondrial ossification whereas long bones such as the

103 humerus and femur form via endochondral ossification, where cartilage is replaced by bone (Ross

104 \& Pawlina 2011; Scheuer et al. 2000). Regardless of its method of formation, bone growth in

105 length happens via cartilaginous growth plates, which fuse in later life, and in diameter by

106 periosteal apposition, enabling the bone to withstand increasing loads (Ross \& Pawlina 2011).

107 Density can also vary throughout the bone, with the shaft of long bones, for example, having a

108 greater density than their extremities (Stiner 2004).

109 Our study investigated the bone growth and localised thickness of the guinea pig scapula,

110 humerus and femur. The rate of growth and the localised thickness are not known for these bones,

111 despite the frequency at which guinea pigs present in veterinary clinics with broken/fractured

112 limb bones. The scapula, along with the humerus, forms the shoulder joint. Similarly to the cat,

113 but unlike other domestic species, the scapula has a small clavicle attaching it to the manubrium

114 sterni. The scapula is a triangular shape and divided by a spine that runs over its lateral surface,

115 into a supraspinous and infraspinous fossa (Dyce et al. 2010). The distal part of the scapula ends

116 in the glenoid cavity, which serves as a surface for articulation with the head of the humerus,

117 forming the shoulder joint (Dyce et al. 2010). The humerus is comprised of the head,

118 contributing to the shoulder joint, and the articular condyle, part of the elbow joint (Dyce et al.

119 2010). Other notable features include the greater and lesser tubercle, the medial and lateral

120 epicondyles and the olecranon fossa (König \& Liebich 2014). The femur articulates with the

121 pelvis via its head forming the hip joint, and caudally with the tibia via its condyles to form the

122 stifle joint (Dyce et al. 2010). It is the strongest long bone of the skeleton and comprises the

123 proximal part of the hind limb with notable features including the greater and lesser trochanter

124 and the trochanteric fossa (König \& Liebich 2014). This study investigates the attributes and

125 growth of three key limb bones, the scapula, humerus and femur. Clinicians and health care

126 advisors alike frequently highlight the importance of not dropping the guinea pig due to the

127 number of limb fractures and breaks that they observe in clinic (Richardson 2003). This study

128 aims to increase the information known about the limb bones, whilst showing how and when

129 development is occurring, in addition to providing localised bone thickness information. 
130 The aims of this study were to utilise microCT technology to measure guinea pig bone 131 dimensions and map bone local thickness in neonates through to adulthood. Although present 132 literature states that adult weight is achieved at 8-12 months (Hubrecht \& Kirkwood 2010), bone 133 growth and local thickness has not been elucidated despite its importance to guinea pig 134 husbandry and clinical care. It is important to highlight that this paper investigates female guinea

135 pigs for a number of reasons. Differences in bone development have been attributed to sex and 136 neuter status (May et al. 1991; Perry et al. 2014; Root et al. 1997) but the additional strain of 137 lactation and pregnancy in the female may further decrease calcium content of bones (Horwits \& 138 Smith 1990) and may therefore increase the potential of bone damage in this sex. In the pet and 139 meat industry a greater number of female guinea pigs are present. For example an increased 140 number of females are observed in the meat industry, with around 1 male to every 12 females 141 generally accepted as the norm (Koeslag 1989; Nuwanyakpa et al. 1997). Guinea pigs are herd 142 animals in the wild and live in family units with a dominate male, but males that are strangers 143 will frequently fight, therefore they are more difficult to house together as pets (Donnelly 2010), 144 resulting in pet owners being more likely to choose a male/female or female/female pair, or a 145 group of females. It should also be highlighted that males may not show the same growth rates or 146 bone thickness, however the full weight of 900-1200 $\mathrm{g}$ for males as opposed to 700-1100 $\mathrm{g}$ for the 147 females, is still achieved at 8-12 months (Behrend 2008; Hubrecht \& Kirkwood 2010; Meredith 148 \& Redrobe 2010). Three methods of bone dimension measurement were utilised - a traditional 149 manual calliper method, a manual measurement of microCT images and an automated microCT 150 analysis. A further aim was to assess the location and number of nutrient foramina and the course 151 of the nutrient canal in every bone, and report on the abundance of both the supratrochlear 152 foramen and the supracondylar foramen in the humerus. 


\section{Materials and Methods}

\section{Sample collection}

155 Naturally deceased, entire female guinea pigs with known medical and husbandry backgrounds 156 were collected under ethical permissions obtained from The University of Nottingham in 157 accordance with the British Home Office laws and the Veterinary Surgeons Act. All animals

158 were fed on standard, commercially available guinea pig food $\mathrm{ad}$. lib. Bones were extracted using 159 manual dissection and grouped according to age - 0-1 month $(<1 \mathrm{~m} ; \mathrm{n}=5)$, 1-3 months $(<3 \mathrm{~m}$; $160 \mathrm{n}=4)$, 3-6 months $(<6 \mathrm{~m} ; \mathrm{n}=4), 6$ months- 1 year $(<1 \mathrm{yr} ; \mathrm{n}=5)$ and $1-4$ years $(<4 \mathrm{yr} ; \mathrm{n}=5)$. The right 161 and left scapula, humerus and femur from each guinea pig were analysed.

\section{MicroCT and bone analysis}

163 Three types of bone measurement were carried out 1) manual bone measurementsas described in 164 Figure 1 using World Precision (UK) digital callipers calibrated to three decimal places. 2) Bone 165 measurements as described in Figure 1 using micro CT images and software. 3) Automated 166 microCT measurements to find the maximal height, depth, width, surface area and volume.

167 Measurements 1 and 2 were compared to ensure no discrepancy between manual and automated 168 methods,

169 Prior to scanning, individual bones were carefully wrapped in thin sheets of x-ray transparent 170 polyethylene packing foam and placed in 40mm diameter x 50mm height plastic specimen jars.

171 Depending on the size of the bones, each jar could accommodate up to 12 individual bones. Each

172 jar was scanned using a GE Phoenix Nanotom S, X-ray microCT system (GE Sensing and 173 Inspection Technologies GmbH, Wunstorf, Germany). The scan consisted of the collection of 1741200 angular projection images in 'Fast' mode at an electron acceleration energy of $110 \mathrm{kV}$ and $175160 \mu \mathrm{A}$ current. The resulting spatial resolution of the scan to fit the entire pot in the field of view 176 was $24.24 \mu \mathrm{m}$. Scans were performed in approximately 30 minutes. Following tomographic 177 reconstruction using Datos rec v1.5 (GE Sensing and Inspection Technologies GmbH, Wunstorf, 178 Germany), individual bones were virtually extracted (segmented) from the 3D volumetric data 179 based on their higher x-ray attenuation from the low density packing materials using a 180 combination of object calibration and region growing tools in VGStudioMax V2.2. software 181 (Volume Graphics GmbH, Heidelberg, Germany). The bone measurements (see Fig 1), volume 182 and surface area of the extracted volumes was measured automatically using the isosurface 183 calibration values in the software. Bone maximal length and width was manually measured using 
184 the calliper tool in VGStudioMax XY image stack data for each bone was exported in 8 bit 185 grayscale tiff image format. Bone local thickness was measured using the BoneJ (Doube et al. 186 2010) plugin for the open source image quantification and analysis software ImageJ 1.44 187 (Schneider et al. 2012). Compact bone local thickness heat map images were visualised in 188 VGStudioMax. Bone dimensions, volumes and densities were analysed using ANOVA using 189 SPSS (V16; f value 0.778 , alpha 0.05 , power $80 \%$ ) statistical software, $\mathrm{P}<0.05$ was considered as 190 a significant difference.

191 Nutrient foramina and canals and the humeral supratrochlear and supracondylar foramina were 192 assessed using both sequential scan $\mathrm{x}$-rays and 3D reconstructions. Nutrient foramina were 193 classified as a cavity that fully breached the entire bone wall, the location of each foramen was 194 recoded alongside the course of the nutrient canal through the bone. Each humerus was also 195 assessed for the presence of both a supratrochlear foramen and a supracondylar foramen. 


\section{Results and Discussion}

\section{Bone development}

198 A previous study compared CT scanning measurements to standard scientific callipers or 199 assessing the skull base and the craniomaxillofacial dimensions in five humans (Citardi et al.

200 2001). CT measurements were found to be more accurate and had a better representation of bone 201 anatomy, however there was little significant difference in results, with $\mathrm{P}$ values ranging from 2020.06 to 1.0 (Citardi et al. 2001). In order to ensure that a similar situation was observed in the 203 smaller guinea pig bone, both microCT and manual measurements were carried out on the 204 scapula, humerus and femur. Our data showed non-significant $(\mathrm{P}>0.05)$ variations ranging from $20596-110 \%$ for each measurement, with $60.5 \%$ of the data falling within $5 \%$ range of the mean. 206 The larger differences, although non-significant, were observed on the femur (smallest bone), 207 specifically the length from the head to the medial condyle of the femur (also one of the smallest 208 measurements). Therefore $\mathrm{CT}$ data was used to compare bone growth data (Fig 2). In addition to 209 data being presented in Figures 2-9, raw data is supplied in Tables S1-S5.

210 Significant differences $(\mathrm{P}<0.05$ to $\mathrm{P}<0.0001)$ in scapula measurements were observed between all 211 ages, for all four measurements (as described in Fig 1, values given in Fig 2A and Table S1)

212 except between 1 year and 4 year old guinea pigs in the width from cranial to caudal angle and 213 width of the elbow joint (Fig 2A, Tables S1 and S2, measurement 2, P $>0.05$ ). The maximal 214 width and length were significantly increased at 4 years old in comparison to 1 year old (Fig 3A, $215 \mathrm{P}<0.05$ ) as were the scapula volume and surface area (Figs $3 \mathrm{~B}$ and $\mathrm{C}, \mathrm{P}<0.004$ and $\mathrm{P}<0.0001$ 216 respectively).

217 Significant differences in humeri measurements (as described in Fig 1) were observed between 218 all ages in all measurements (measurements shown in Fig 2B and Tables $\mathrm{S} 1$ and $\mathrm{S} 3, \mathrm{P}<0.008$ to $219 \mathrm{P}<0.0001)$ with the exception of width between the head and greater tubercle between 1 year and 2204 years and the width of the elbow joint between 3 and 6 months. Overall however, the maximal 221 width, depth, length, volume and surface areas did not significantly increase between 1 and 4 222 years old (Fig 4, P $>0.05$ ), therefore differing growth rates were observed in comparison to the 223 scapula.

224 The femur measurements showed significant differences in measurements described in Fig 1 225 between the different age groups (Figs $2 \mathrm{C}$ and 5 and Tables $\mathrm{S} 1$ and $\mathrm{S} 4, \mathrm{P}<0.018$ to $\mathrm{P} 0.0001$ ). 
226 Although the length from the head to the medial condyle and maximal width increased from 1

227 year to 4 years old, the maximal length and depth did not (Figs $2 \mathrm{C}$ and $5 \mathrm{~A}$ ). In contrast to the

228 humerus though, the volume and surface area of the femur were significantly increased from 1

229 year to 4 years (Figs 5B and C, Table S4, $\mathrm{P}<0.004$ and $\mathrm{P}<0.0001$ respectively).

230

231 Mean scapula local thickness (Figs 6 and 7 and Table S5) significantly increased until 6 months

232 old $(\mathrm{P}<0.003)$, but appeared to stabilise thereafter before a slight decrease was observed at 4

233 years old, whereas the maximum scapula local thickness in younger guinea pigs was significantly

234 lower in animals aged 6 months in comparison to 1 year/4 year old bones (Fig 7A, $\mathrm{P}<0.005$ to

$235 \mathrm{P}<0.0001)$. Humerus local thickness, both mean and maximum, also significantly increased from

2361 month to 4 years $(\mathrm{P}<0.0001$ and $\mathrm{P}<0.002$ respectively), but only the mean significantly

237 increased in the latter stages from 6 months to 4 years (Fig 7B, $\mathrm{P}<0.023$ ). Femur local thickness

238 mean and maximum significantly increased until 1 year $(\mathrm{P}<0.002)$ and 6 months $(\mathrm{P}<0.033)$

239 respectively but no differences were observed beyond these ages (Fig 7C).

240 The differential compact bone local thickness can be observed in detail across the developing

241 scapula, humerus and femur in Figure 6 and Table S5. It was interesting to note that higher

242 growth rates were observed in the scapular (flat bone) between years 1 and 4 in comparison to the

243 long bones (Fig 8A, see also Figs 2-5), however the bone local thickness was more likely to

244 increase between these time points in the long bones in comparison with the scapula (Fig 8B, see

245 also Fig 7). Despite these overall increases, it was noted that the older bones had a far greater

246 variation in localised bone thickness, resulting in greater extremes of thickness being observed in

247 comparison to younger bones (Figs 6-8 and Table S5).

\section{Nutrient, supratrochlear and supracondylar foramina}

249 The nutrient foramen and canal are the result of the invading nutrient artery during fetal

250 development (Payton 1934). It was noted in our study that every bone had between 2 and 5

251 nutrient foramina; no bones contained a singular foramen. Within the scapula, the primary

252 foramen is commonly located in most species at the lateral aspect of the infraspinous fossa,

253 whilst secondary foramina (if present) can be located on either the infrasinous fossa or the

254 subscapular fossae (Scheuer et al. 2000). This was also observed in our study, but secondary

255 foramina were also located on the scapula spine and acromion. Within the guinea pig long bones

256 (femur and humerus), the primary nutrient foramina were located in the proximal or distal third 
257 of the diaphysis. Further foramina (up to four more per bone) were located: above the trochlear

258 foramen and on the greater tubercle (humerus), and on the head and the shaft of the head (femur).

259 This positioning is similar to most animals where within long bones, the primary nutrient

260 foramen is often located in either the proximal or distal third of the diaphysis, with the canal

261 running obliquely into the medulla (Payton 1934). Previous research in the pig found that in the

262 humerus, the foramen is located in the distal third of the bone and the canal directed proximally,

263 while in the femur the foramen is located in the proximal third and the canal runs distally (Payton

264 1934). In relation to the multiple foramina (Fig 9) observed in the guinea pig bones, it has been

265 reported that each bone generally has a single nutrient foramen, however studies on the canine

266 femur found that only $6.2 \%$ of cases contained a single foramen, while more frequently, two or

267 more foramina existed in a single bone (Ahn 2013). Our serial x-ray data showed that every

268 nutrient canal, regardless of bone, position or age, travelled in an oblique direction in the female

269 guinea pig. The oblique direction observed concurs with, and supports, previous studies in both

270 the guinea pig and most other species (De Bruyn et al. 1970; Payton 1934).

The lower end of the humerus has two large fossae, the olecranon fossa and the coronoid fossa, separated by a thin bony plate that rarely bears an opening known as supratrochlear foramen (STF). A STF was observed in all of the female guinea pig humeri $(n=46)$, left and right regardless of age (Fig 9). The SFT is formed when the olecranon fossa at the caudal aspect of the distal humerus is so deep that is meets the radial fossa on the bone's cranial aspect. The SFT is closed by a membrane of connective tissue and no major blood vessels of nerves pass through the foramen. The presence of the SFT within mammals is very variable and is linked to the range of mobility in the elbow joint. Most hystricognath rodents have a STF, which is likely to facilitate full extension of the elbow joint in terrestrial locomotion, while in arboreal species the olecranon fossa is more often shallow and a SFT is not formed (Candela \& Picasso 2008). In humans there is some variability in the presence of an SFT. A study of the humerus in North Indians found that the presence of the STF varied within the sampled population from not being present at all, to present bilaterally or only in one femur (Mahajan 2011). 26\% of the humeri had a STF, with a higher frequency in females and in the left humerus (Mahajan 2011). It has been hypothesised that the presence of a STF may produce stress, altering the fracture lines and possibly increasing supracondylar fracture rates, even in low-energy trauma (Sahajpal \& Pichora 2006). This could be of clinical concern in guinea pigs as $58 \%$ of all human paediatric elbow fractures are in the supracondylar area of the humerus (Houshian et al. 2001). 
271 It was also noted that the supracondylar foramen was absent in all 46 guinea pig humeri. The 272 supracondylar or entepicondylar foramen is a foramen proximal to the medial epicondyle of the

273 humerus. The median nerve and brachial artery pass through this foramen. The supracondylar

274 foramen is an ancestral structure in mammals and has been lost independently in several

275 mammalian clades during mammalian evolution (Polly 2007). The foramen is absent in the

276 guinea pig, as well as in other hystricognath rodents (Candela \& Picasso 2008). 


\section{Conclusions}

278 Understanding normal bone growth and development in the guinea pig is essential, especially in

279 relation to movement and homeostasis as a store of calcium and phosphorus. Guinea pigs suffer

280 from a number of bone disorders including metabolic bone disease - conditions that develop

281 following prolonged calcium or vitamin D deficiency, or an improper ratio of calcium to

282 phosphorus in the diet (Terril \& Clemons 1997). Imbalances have resulted in reports of reduced

283 growth rate, pathological changes of the animal's skeleton and osteodystrophia fibrosa resulting

284 from nutritional secondary hyperparathyroidism (Rapsch Dahinden et al. 2009; Schwarz et al.

285 2001). Bone disorders can also manifest from hypovitaminosis C, a dietary insufficiency of

286 vitamin $\mathrm{C}$ for just 2 to 3 weeks can result in lameness or pain due to intra-articular haemorrhage,

287 anorexia, weight loss and general unthriftiness, progressing to death if untreated $(\mathrm{Gad} 2013$;

288 Richardson 2003; Terril \& Clemons 1997) and if combined with vitamin E deficiency the time

289 can drop to just a few days (Hill et al. 2003). Disorders such as osteoporosis, common in this

290 species (Bendele et al. 1989), accelerate bone composition and modelling changes and decrease

291 the bone's density significantly, however this can also be attributed to normal age-related changes

292 (Bilezikian et al. 2008). In order to compare and understand disease states, normal bone growth,

293 development and morphology must be categorised and our study has added to the data available

294 on normal bones throughout development.

295 Differences in bone development have also been attributed to sex and neuter status (May et al.

296 1991; Perry et al. 2014; Root et al. 1997), therefore it is important to highlight that the male

297 guinea pig rates of growth and bone development characteristics may differ in relation to our

298 study, as may neutered females. In addition to this, further variation may be seen within the

299 female as lactation and pregnancy are known to alter calcium content of bones (Horwits \& Smith

300 1990).

301 Over the years a number of techniques have been used to investigate bone and unravel the 302 complex biology of disorders, for example clinical CT, magnetic resonance and histology.

303 MicroCT holds some benefits such as higher resolution or speed of sample processing in

304 comparison with other techniques but with the caveat that it can only be used in non-living

305 specimens (due to significantly increased $\mathrm{x}$-ray radiation dose required for microCT in relation to 306 clinical CT scanning). 
307 Our study is the first to show the growth rates and local bone thicknesses for the scapula,

308 humerus and femur in the developing guinea pig. Despite sexual maturity occurring at around 6-

30910 weeks, and full animal weight being achieved at 8-12 months, the scapula, humerus and femur

310 continue to grow, and the local bone thicknesses alter beyond 1 year. This paper is also the first

311 to show the absence of the supracondylar foramen and the unusual presence of the supratrochlear

312 foramen in the humerus of this species, which may in turn affect fracture rates and locations

313 within the humerus. Understanding guinea pig bone development and anatomy can help inform

314 clinical and husbandry practice, especially in relation to bone thickness and fractures.

\section{Acknowledgements:}

316 The authors would like to thank the owners of the guinea pigs for donating their animals in order

317 to further the understanding of this species. We would also like to thank the School of Veterinary

318 Medicine and Science technical team for providing sample storage and space for the study.

\section{References}

320

321

322

323

324

325

326

327

328

329

330

331

332

333

334

335

336

337

338

339

340

341
Ahn D. 2013. Anatomical study on the diaphyseal nutrient foramen of the femur and tibia of the german shepherd dog. Journal of Veterinary Medical Science 75:803-808.

Behrend K. 2008. Guinea Pigs: A Complete Pet Owner's Manual. USA: Barron's Educational Series Inc.

Bendele AM, White SL, and Hulman JF. 1989. Osteoarthrosis in guinea pigs: histopathologic and scanning electron microscopic features. Laoratory Animal Science 39:115-121.

Bialek P, Parkington J, Li X, Gavin D, Wallace C, Zhang J, Root A, Yan G, Warner L, Seeherman HJ, and Yaworsky PJ. 2014. A myostatin and activin decoy receptor enhances bone formation in mice. Bone 60:162-171.

Bilezikian JP, Raisz LG, and Martin TJ. 2008. Principles of Bone Biology. USA: Elsevier Inc.

Burnie D. 2008. Cavy-like rodents. In: Burnie D, ed. Illustrated Encyclopedia Of Animals. UK: Dorling Kindersley, 158.

Candela AM, and Picasso MB. 2008. Functional anatomy of the limbs of erethizontidae (Rodentia, Caviomorpha): Indicators of locomotor behavior in Miocene porcupines. Journal of Morphology 269:552-593.

Citardi MJ, Herrmann B, Hollenbeak CS, Stack BC, Cooper M, and Bucholz RD. 2001. Comparison of scientific calipers and computer-enabled CT: Review for the measurement of skull base and craniomaxillofacial dimensions. Skull Base 11:5-11. 
342

343

344

345

346

347

348

349

350

351

352

353

354

355

356

357

358

359

360

361

362

363

364

365

366

367

368

369

370

371

372

373

374

375

376

377

378

379

380

381

382

383

384

385

386

387

388

389

390

391

392

393

De Bruyn PP, Breen PC, and Thomas TB. 1970. The microcirculation of the bone marrow. Anatomical Record 168:55-68.

Donnelly TM. 2010. The Merck Veterinary Manual. USA: Merck.

Doube M, Klosowski MM, Arganda-Carreras I, Cordelieres FP, Dougherty RP, Jackson JS, Schmid B, Hutchinson JR, and Shefelbine SJ. 2010. BoneJ: Free and extensible bone image analysis in Imagej. Bone 47:1076-1079.

Dyce KM, Sack WO, and Wensing CJG. 2010. Textbook of Veterinary Anatomy: Saunders Elsevier.

Frost HM. 1997. Defining osteopenias and osteoporoses: Another view (with insights from a new paradigm). Bone 20:385-391.

Gad SC. 2013. Animal Models in Toxicology. USA: CRC Press.

Harkness JE, Turner PV, VandeWoude S, and Wheler CL. 2010. Harkness and Wagner's Biology and Medicine of Rabbits and Rodents. USA: Wiley-Blackwell.

Hill KE, Montine TJ, Motley AK, Li X, May JM, and Burk RF. 2003. Combined deficiency of vitamins $\mathrm{E}$ and $\mathrm{C}$ causes paralysis and death in guinea pigs. American Journal of Clinical Nutrition 77:1484-1488.

Horwits LK, and Smith P. 1990. A radiographic study of the extent of variation in cortical bone thickness in Soay sheep. Journal of Archaeological Science 17:655-664.

Hounsfield GN. 1973. Computerized transverse axial scanning (tomography) .1. Description of system. British Journal of Radiology 46:1016-1022.

Houshian S, Mehdi B, and Larsen MS. 2001. The epidemiology of elbow fracture in children: analysis of 355 fractures, with special reference to supracondylar humerus fractures. Journal of Orthopaedic Science 6:312-315.

Hubrecht R, and Kirkwood J. 2010. The UFAW Handbook on the Care and Management of Laboratory and Other Research Animals. USA: WileyBlackwell.

Koeslag JH. 1989. The guinea pig as meat producer. Available at http://www.agriculturesnetwork.org/magazines/global/discussion-onsustaining-agriculture/the-guinea-pig-as-meat-producer.

König HE, and Liebich H. 2014. Veterinary Anatomy of Domestic Mammals: Textbook and Colour Atlas. Germany: Schattauer GMBH.

Mahajan A. 2011. Supratrochlear foramen; study of the humerus in North Indians. The Professional Medical Journal 18(1):128-132.

May C, Bennett D, and Downham DY. 1991. Delayed Physeal Closure Associated with Castration in Cats. Journal of Small Animal Practice 32:326-328.

Meredith A, and Redrobe S. 2010. BSAVA Manual of Exotic Pets: British Small Animal Veterinary Association.

Metscher BD. 2009. MicroCT for comparative morphology: simple staining methods allow high-contrast 3D imaging of diverse non-mineralized animal tissues. BMC Physiology 9:11.

Mitchell M, and Tully T. 2009. Manual of Exotic Pet Practice. USA: Saunders.

Morales E. 1995. The guinea pig: healing, food, and ritual in the Andes. USA: University of Arizona Press.

NRC. 1991. National Research Council: Microlivestock: Little-Known Small Animals with a Promising Economic Future. USA: John Wiley \& Sons.

Numbela ER, and Valencia CR. 2003. Guinea pig management manual. USA: Benson Agriculture and Food Institute.

Nuwanyakpa M, Lukefahr SD, Gudahl D, and Ngoupayou JD. 1997. The current stage and future prospects of guinea pig production under smallholder conditions in West Africa; 1. Global overview. Livestock Research for Rural Development 9:951.

PeerJ reviewing PDF | (v2014:09:2645:1:0:NEW 17 Sep 2014) 
394

395

396

397

398

399

400

401

402

403

404

405

406

407

408

409

410

411

412

413

414

415

416

417

418

419

420

421

422

423

424

425

426

427

428

429

430

431

432

433

434

435

436

437

438

439

440

441

442

443

444

445

Payton CG. 1934. The position of the nutrient foramen and direction of the nutrient canal in the long bones of the madder-fed pig. Journal of Anatomy 68:500510.

Perry KL, Fordham A, and Arthurs Gl. 2014. Effect of neutering and breed on femoral and tibial physeal closure times in male and female domestic cats. J Feline Med Surg 16:149-156.

PFMA. 2013. Pet Food Manufacturer's Association: Pet Population 2013. Pet Food Manufacturer's Association

Polly PD. 2007. Limbs in mammalian evolution In: Hall BK, ed. Fins to Limbs: Evolution, Development, and Transformation. USA: The University of Chicago Press.

Rapsch Dahinden C, Klawitter A, Sagawe J, and Fehr M. 2009. [Course of Osteodystrophia fibrosa generalisata in a satin guinea pig]. Schweizer Archiv fur Tierheilkunde 151:233-237.

Richardson VCG. 2003. Diseases of Small Domestic Rodents. USA: Wiley-Blackwell.

Ritman EL. 2011. Current status of developments and applications of micro-CT. Annual Review of Biomedical Engineering 13:531-552.

Root MV, Johnston SD, and Olson PN. 1997. The effect of prepuberal and postpuberal gonadectomy on radial physeal closure in male and female domestic cats. Veterinary Radiology and Ultrasound 38:42-47.

Ross MH, and Pawlina W. 2011. Histology A Text and Atlas: with correlated cell and molecular biology. USA: Lippincott Williams and Wilkins.

Sahajpal DT, and Pichora D. 2006. Septal aperture: an anatomic variant predisposing to bilateral low-energy fractures of the distal humerus. Canadian Journal of Surgery 49:363-364.

Scheuer I, Black S, and Cunningham C. 2000. Developmental Junenile Osteology. UK: Elsevier Academic Press.

Schneider CA, Rasband WS, and Eliceiri KW. 2012. NIH Image to ImageJ: 25 years of image analysis. Nature Methods 9:671-675.

Schwarz T, Stork CK, Megahy IW, Lawrie AM, Lochmuller EM, and Johnston PE. 2001. Osteodystrophia fibrosa in two guinea pigs. Journal of American Veterinary Medical Association 219:63-66, 49.

Sjaastad OV, Hove K, and Sand O. 2010. Physiology of Domestic Animals: Scandinavian Veterinary Press.

Stiner MC. 2004. A comparison of photon densitometry and computed tomography parameters of bone density in ungulate body part profiles. Journal of Taphonomy 2:117-145.

Tao F, Fu F, You F, Ji Z, Wen J, Shi X, Dong X, and Yang M. 2014. The correlation between dielectric properties and microstructure of femoral bone in rats with different bone qualities. Annals of Biomedical Engineering 42:1238-1249.

Terril LA, and Clemons DJ. 1997. The Laboratory Guinea Pig. USA: CRC Press LLC.

USDA. 2011. United States Department of Agriculture: Annual report animal usage by fiscal year.

Uzun H, Curthoys IS, and Jones AS. 2007. A new approach to visualizing the membranous structures of the inner ear - high resolution X-ray microtomography. Acta Otolaryngology 127:568-573.

Willett TL, Kandel R, De Croos JN, Avery NC, and Grynpas MD. 2012. Enhanced levels of non-enzymatic glycation and pentosidine crosslinking in spontaneous osteoarthritis progression. Osteoarthritis Cartilage 20:736-744.

Zoetis T, Tassinari MS, Bagi C, Walthall K, and Hurtt ME. 2003. Species comparison of postnatal bone growth and development. Birth Defects Research part BDevelopmental and Reproductive Toxicology 68:86-110.

PeerJ reviewing PDF | (v2014:09:2645:1:0:NEW 17 Sep 2014) 


\section{Figure 1}

Figure 1: Gross anatomical photographs indicating measurements calculated.

A) Scapula; 1- length of the bone; 2- length of the spine; 3- width from cranial to caudal angle; 4- width of the shoulder joint. B) Humerus; 1 -length from the head to the elbow; 2width from the head to the greater tubercle; 3- width of the elbow joint and C) Femur; 1 overall length from the head to the medial condyle.

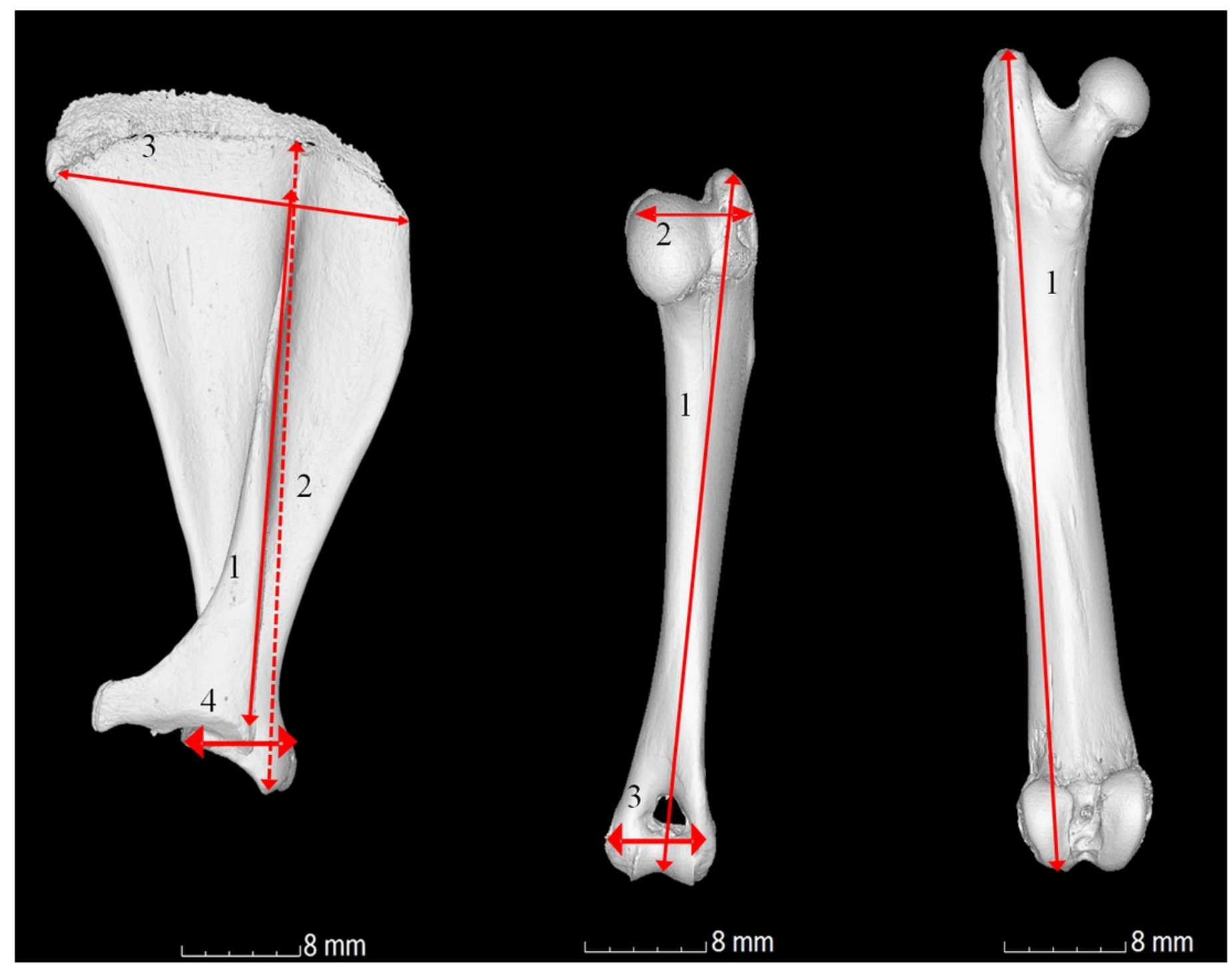




\section{Figure 2}

Figure 2 Manual measurements aided by micro-CT.

Measurements of guinea pig bones aged 0-1 month $(<1 \mathrm{~m}), 1-3$ months $(<3 \mathrm{~m}), 3-6$ months $(<6 \mathrm{~m}), 6$ months-1 year ( $<1 \mathrm{yr})$ and $1-4$ years $(<4 \mathrm{yr})$. A) Scapula, B) humerus and C) femur with associated ANOVA with post-hoc $P$ value tables. NS=not significant. Mean \pm standard error of the mean error bars. 
PeerJ Reviewing Manuscript

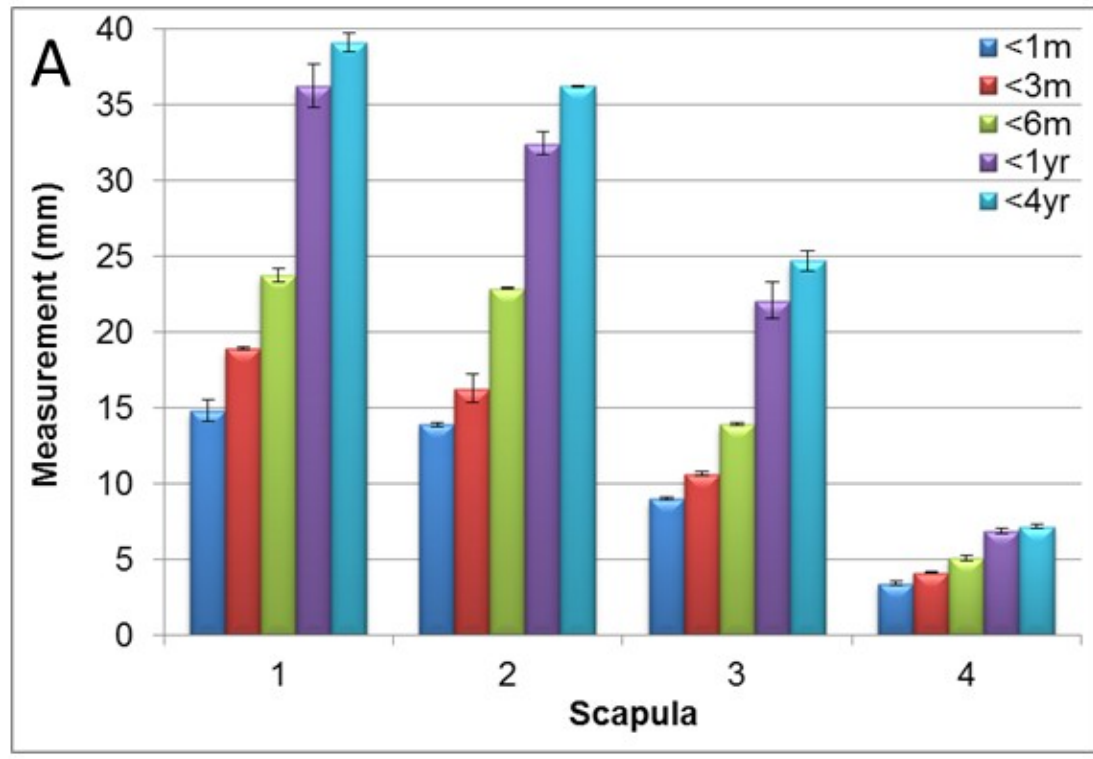

\begin{tabular}{|l|c|c|c|c|}
\hline Scap 1(mm) & $<3 \mathrm{~m}$ & $<6 \mathrm{~m}$ & $<1 \mathrm{yr}$ & $<4 \mathrm{yr}$ \\
\hline$<1 \mathrm{~m}$ & 0.002 & 0.0001 & 0.0001 & 0.0001 \\
\hline $3 \mathrm{~m}$ & $\mathrm{X}$ & 0.001 & 0.0001 & 0.0001 \\
\hline $6 \mathrm{~m}$ & & $\mathrm{X}$ & 0.0001 & 0.0001 \\
\hline $1 \mathrm{yr}$ & & & $\mathrm{X}$ & $\mathrm{NS}$ \\
\hline Scap 2(mm) & $<3 \mathrm{~m}$ & $<6 \mathrm{~m}$ & $<1 \mathrm{yr}$ & $<4 \mathrm{yr}$ \\
\hline$<1 \mathrm{~m}$ & 0.049 & 0.0001 & 0.0001 & 0.0001 \\
\hline $3 \mathrm{~m}$ & $\mathrm{X}$ & 0.0001 & 0.0001 & 0.0001 \\
\hline$<6 \mathrm{~m}$ & & $\mathrm{X}$ & 0.0001 & 0.0001 \\
\hline$<1 \mathrm{yr}$ & & & $X$ & 0.001 \\
\hline Scap 3(mm) & $<3 \mathrm{~m}$ & $<6 \mathrm{~m}$ & $<1 \mathrm{yr}$ & $<4 \mathrm{yr}$ \\
\hline$<1 \mathrm{~m}$ & $\mathrm{NS}$ & 0.0001 & 0.0001 & 0.0001 \\
\hline$<3 \mathrm{~m}$ & $\mathrm{X}$ & 0.005 & 0.0001 & 0.0001 \\
\hline$<6 \mathrm{~m}$ & & $\mathrm{X}$ & 0.0001 & 0.0001 \\
\hline$<1 \mathrm{yr}$ & & & $X$ & 0.012 \\
\hline Scap 4(mm) & $<3 \mathrm{~m}$ & $<6 \mathrm{~m}$ & $<1 \mathrm{yr}$ & $<4 \mathrm{yr}$ \\
\hline$<1 \mathrm{~m}$ & 0.011 & 0.0001 & 0.0001 & 0.0001 \\
\hline$<3 \mathrm{~m}$ & $\mathrm{X}$ & 0.001 & 0.0001 & 0.0001 \\
\hline$<6 \mathrm{~m}$ & & $\mathrm{X}$ & 0.0001 & 0.0001 \\
\hline$<1 \mathrm{yr}$ & & & $X$ & $\mathrm{NS}$ \\
\hline
\end{tabular}

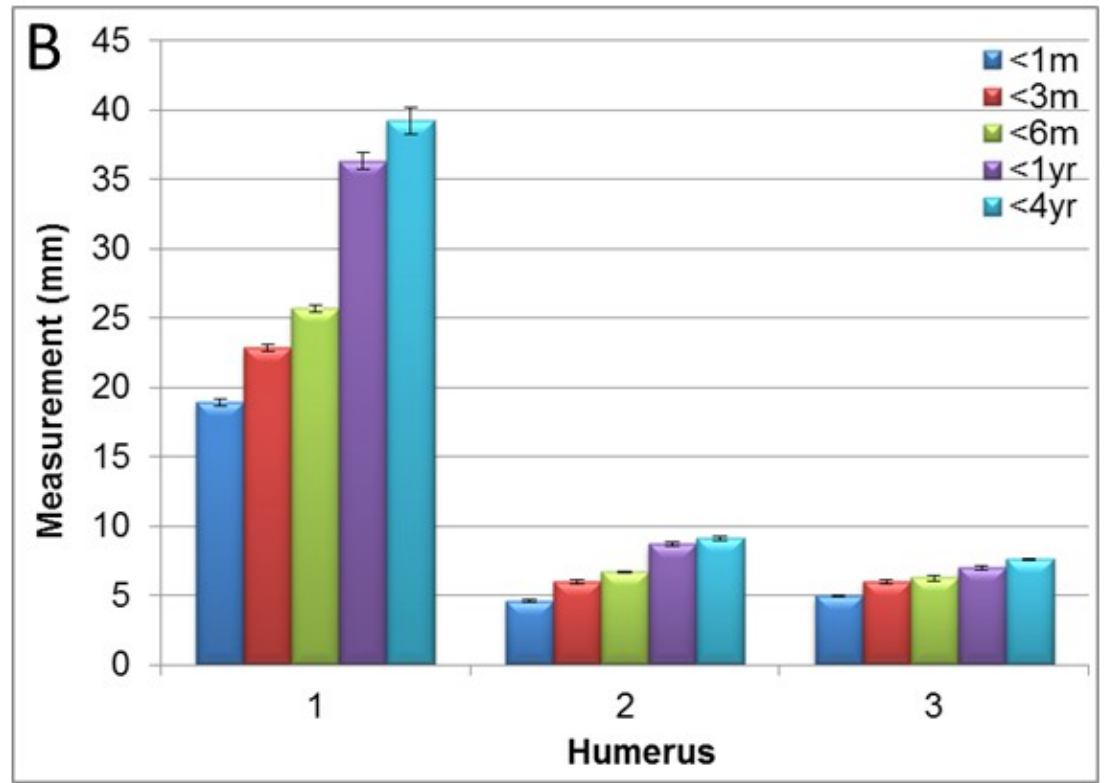

\begin{tabular}{|l|c|c|c|c|}
\hline Hum 1(mm) & $<3 \mathrm{~m}$ & $<6 \mathrm{~m}$ & $<1 \mathrm{yr}$ & $<4 \mathrm{yr}$ \\
\hline$<1 \mathrm{~m}$ & 0.0001 & 0.0001 & 0.0001 & 0.0001 \\
\hline$<\mathrm{m}$ & $\mathrm{X}$ & 0.0001 & 0.0001 & 0.0001 \\
\hline$<6 \mathrm{~m}$ & & $\mathrm{X}$ & 0.0001 & 0.0001 \\
\hline$<1 \mathrm{yr}$ & & & $\mathrm{X}$ & 0.001 \\
\hline Hum 2(mm) & $<3 \mathrm{~m}$ & $<6 \mathrm{~m}$ & $<1 \mathrm{yr}$ & $<4 \mathrm{yr}$ \\
\hline $\begin{array}{l}<\mathrm{m} \\
<3 \mathrm{~m}\end{array}$ & 0.0001 & 0.0001 & 0.0001 & 0.0001 \\
\hline$<6 \mathrm{~m}$ & $\mathrm{X}$ & 0.0001 & 0.0001 & 0.0001 \\
\hline$<1 \mathrm{yr}$ & & $\mathrm{X}$ & 0.0001 & 0.0001 \\
\hline Hum 3(mm) & $<3 \mathrm{~m}$ & $<6 \mathrm{~m}$ & $<1 \mathrm{yr}$ & $<4 \mathrm{yr}$ \\
\hline $\begin{array}{l}<\mathrm{m} \\
<3 \mathrm{~m}\end{array}$ & 0.0001 & 0.0001 & 0.0001 & 0.0001 \\
\hline$<6 \mathrm{~m}$ & $\mathrm{X}$ & $\mathrm{NS}$ & 0.0001 & 0.0001 \\
\hline$<1 \mathrm{yr}$ & & $\mathrm{X}$ & 0.0001 & 0.0001 \\
\hline
\end{tabular}

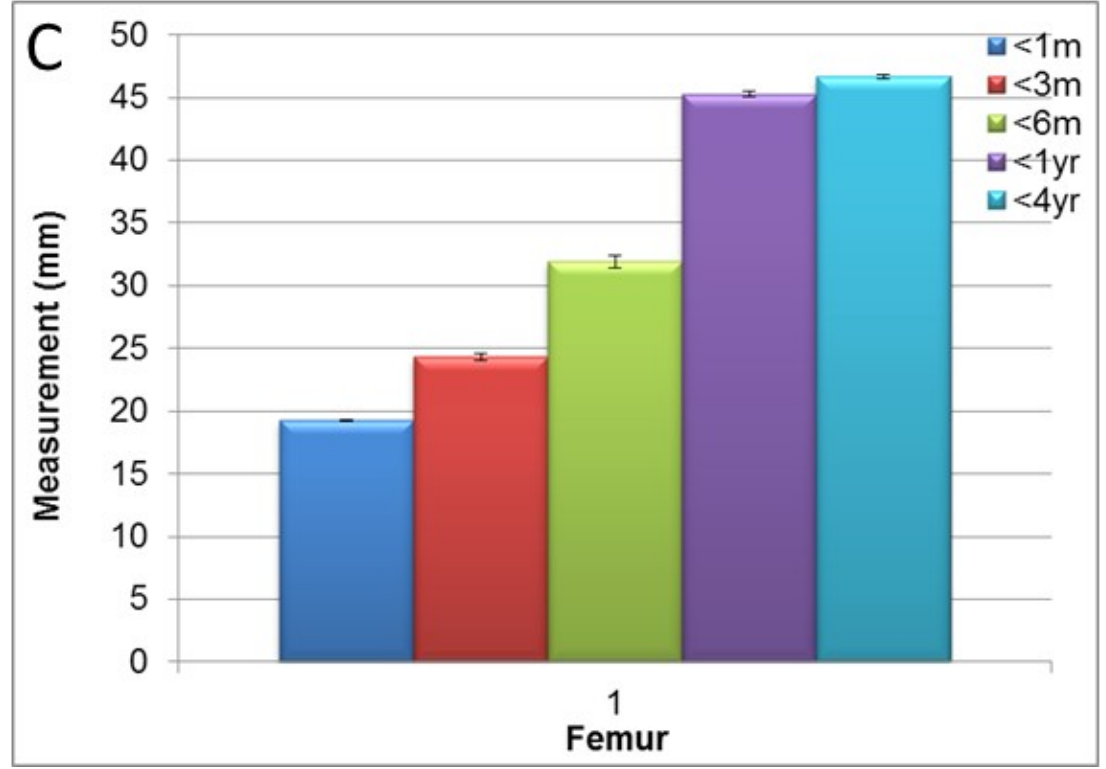

\begin{tabular}{|c|c|c|c|c|}
\hline Femur $(\mathrm{mm})$ & $<3 m$ & $<6 \mathrm{~m}$ & $<1 \mathrm{yr}$ & $<4 \mathrm{yr}$ \\
\hline$<1 \mathrm{~m}$ & 0.0001 & 0.0001 & 0.0001 & 0.0001 \\
\hline$<3 m$ & X & 0.0001 & 0.0001 & 0.0001 \\
\hline$<6 m$ & & $\mathrm{x}$ & 0.0001 & 0.0001 \\
\hline$<1 \mathrm{yr}$ & & & $\mathrm{X}$ & 0.018 \\
\hline
\end{tabular}




\section{Figure 3}

Figure 3 Micro-CT scapula measurements.

Measurements of guinea pig scapula aged 0-1 month $(<1 \mathrm{~m}), 1-3$ months $(<3 \mathrm{~m}), 3-6$ months $(<6 \mathrm{~m}), 6$ months-1 year ( $<1 \mathrm{yr})$ and 1-4 years ( $<4 \mathrm{yr}) . A)$ bone width, depth and length, $B)$ surface area and $C$ ) volume with associated ANOVA with post-hoc $P$ value tables. NS=not significant. Mean \pm standard error of the mean error bars. $S A=$ surface area. 
PeerJ Reviewing Manuscript

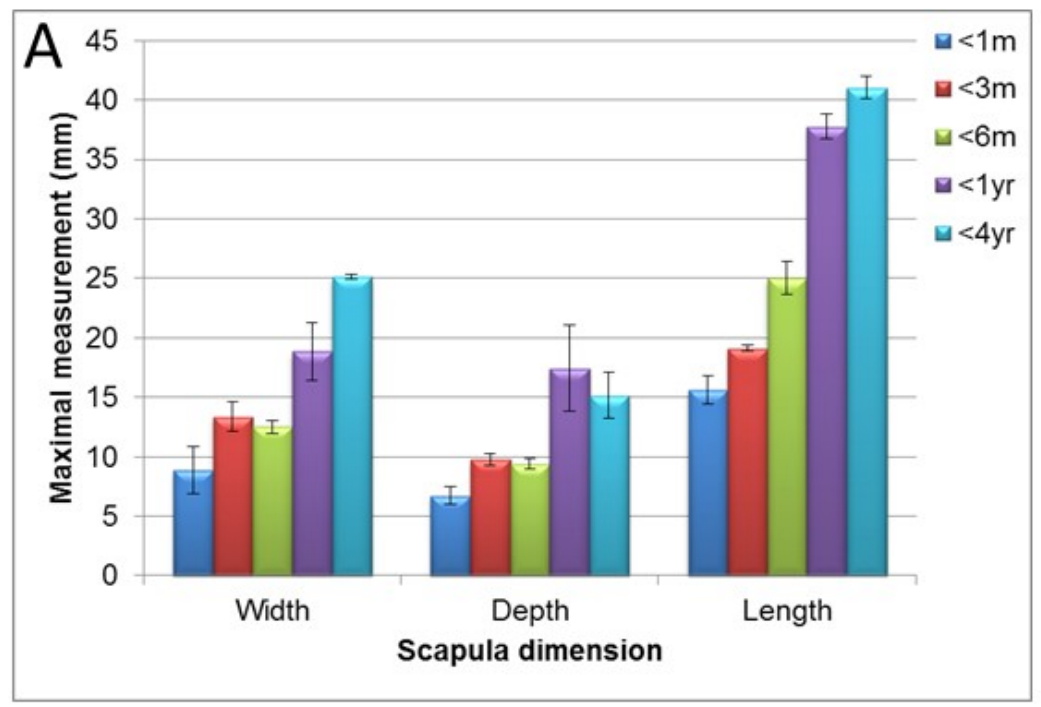

\begin{tabular}{|l|c|c|c|c|}
\hline Width $(\mathrm{mm})$ & $<3 \mathrm{~m}$ & $<6 \mathrm{~m}$ & $<1 \mathrm{yr}$ & $<4 \mathrm{yr}$ \\
\hline$<1 \mathrm{~m}$ & $\mathrm{NS}$ & $\mathrm{NS}$ & 0.0001 & 0.0001 \\
\hline$<3 \mathrm{~m}$ & $\mathrm{X}$ & $\mathrm{NS}$ & 0.047 & 0.001 \\
\hline $6 \mathrm{~m}$ & & $\mathrm{X}$ & 0.005 & 0.0001 \\
\hline$<1 \mathrm{yr}$ & & & $\mathrm{X}$ & 0.011 \\
\hline Depth $(\mathrm{mm})$ & $<3 \mathrm{~m}$ & $<6 \mathrm{~m}$ & $<1 \mathrm{yr}$ & $<4 \mathrm{yr}$ \\
\hline$<1 \mathrm{~m}$ & $\mathrm{NS}$ & $\mathrm{NS}$ & 0.0001 & 0.006 \\
\hline$<3 \mathrm{~m}$ & $\mathrm{X}$ & $\mathrm{NS}$ & 0.033 & $\mathrm{NS}$ \\
\hline$<6 \mathrm{~m}$ & & $\mathrm{X}$ & 0.008 & $\mathrm{NS}$ \\
\hline$<1 \mathrm{yr}$ & & & $\mathrm{X}$ & $\mathrm{NS}$ \\
\hline Length $(\mathrm{mm})$ & $<3 \mathrm{~m}$ & $<6 \mathrm{~m}$ & $<1 \mathrm{yr}$ & $<4 \mathrm{yr}$ \\
\hline$<1 \mathrm{~m}$ & $\mathrm{NS}$ & 0.0001 & 0.0001 & 0.0001 \\
\hline $3 \mathrm{~m}$ & $\mathrm{X}$ & 0.002 & 0.0001 & 0.0001 \\
\hline $6 \mathrm{~m}$ & & $\mathrm{X}$ & 0.0001 & 0.0001 \\
$<1 \mathrm{yr}$ & & & $X$ & 0.038 \\
\hline
\end{tabular}

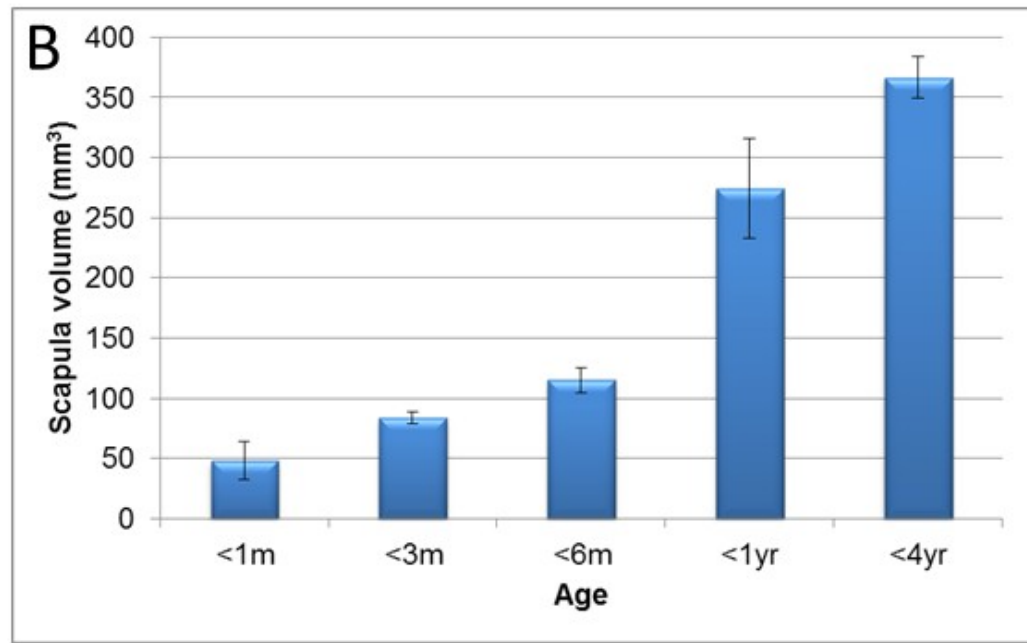

\begin{tabular}{|l|c|c|c|c|}
\hline Volume $\left(\mathrm{mm}^{3}\right)$ & $<3 \mathrm{~m}$ & $<6 \mathrm{~m}$ & $<1 \mathrm{yr}$ & $<4 \mathrm{yr}$ \\
\hline$<1 \mathrm{~m}$ & NS & 0.03 & 0.0001 & 0.0001 \\
$<3 \mathrm{~m}$ & $\mathrm{X}$ & NS & 0.0001 & 0.0001 \\
\hline $6 \mathrm{~m}$ & & $X$ & 0.0001 & 0.0001 \\
\hline $1 \mathrm{yr}$ & & & $X$ & 0.004 \\
\hline
\end{tabular}

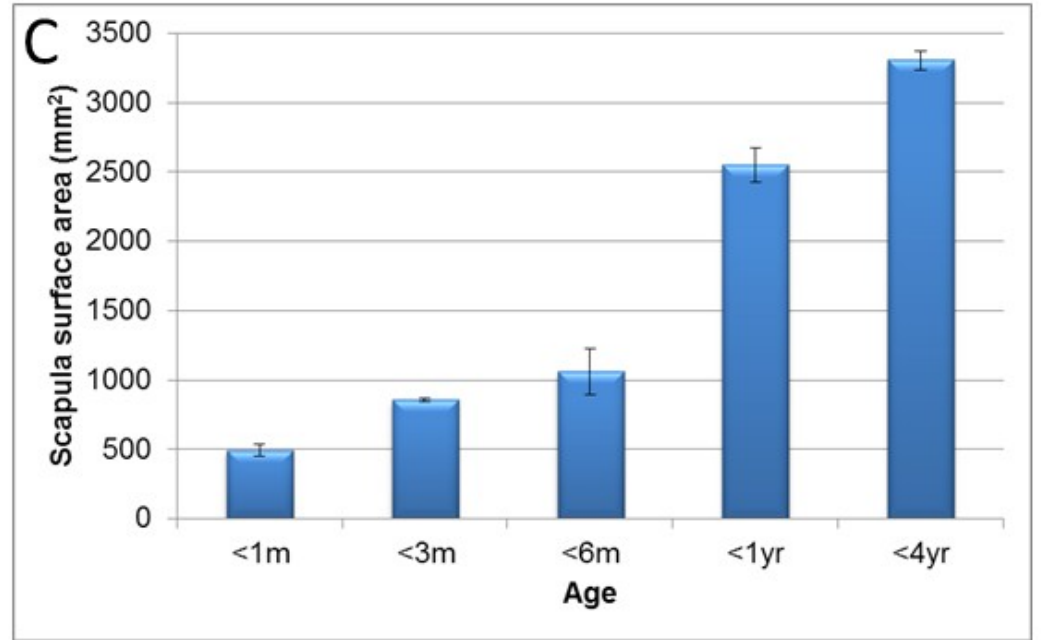

\begin{tabular}{|l|c|c|c|c|}
\hline $\mathrm{SA}\left(\mathrm{mm}^{2}\right)$ & $<3 \mathrm{~m}$ & $<6 \mathrm{~m}$ & $<1 \mathrm{yr}$ & $<4 \mathrm{yr}$ \\
\hline$<1 \mathrm{~m}$ & 0.029 & 0.0001 & 0.0001 & 0.0001 \\
\hline$<3 \mathrm{~m}$ & $X$ & NS & 0.0001 & 0.0001 \\
\hline$<6 \mathrm{~m}$ & & $X$ & 0.0001 & 0.0001 \\
\hline $1 \mathrm{yr}$ & & & $X$ & 0.0001 \\
\hline
\end{tabular}




\section{Figure 4}

Figure 4 Micro-CT humerus measurements.

Measurements of guinea pig humerus aged 0-1 month $(<1 \mathrm{~m}), 1-3$ months $(<3 \mathrm{~m}), 3-6$ months $(<6 \mathrm{~m}), 6$ months-1 year ( $<1 \mathrm{yr})$ and 1-4 years ( $<4 \mathrm{yr}) . A)$ bone width, depth and length, $B)$ surface area and $C$ ) volume with associated ANOVA with post-hoc $P$ value tables. NS=not significant. Mean \pm standard error of the mean error bars. $S A=$ surface area. 
PeerJ Reviewing Manuscript

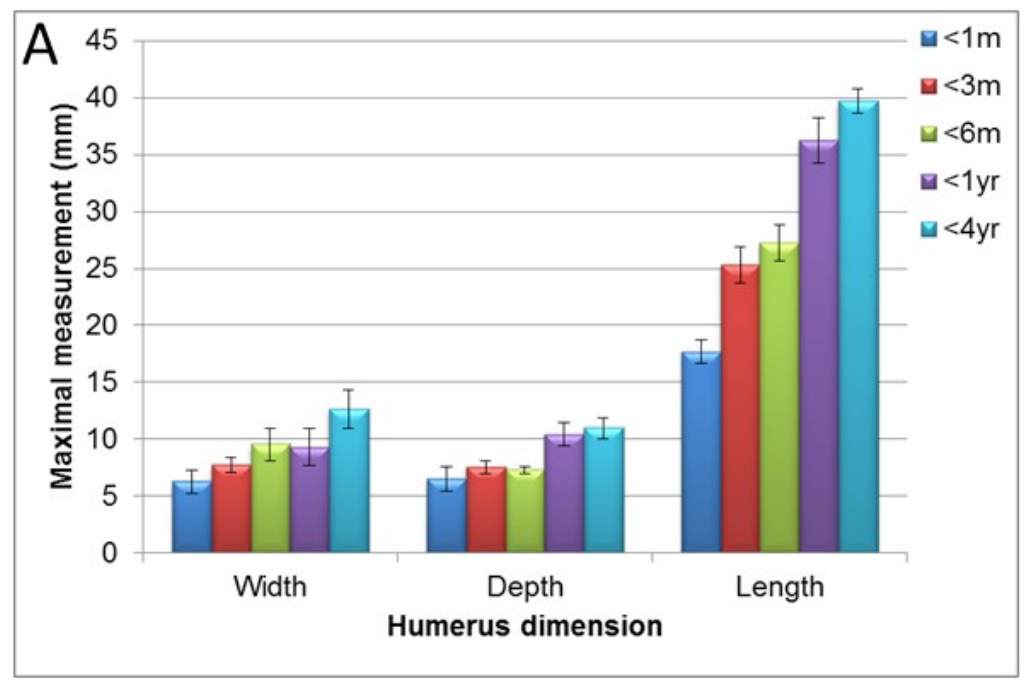

\begin{tabular}{|l|c|c|c|c|}
\hline Width $(\mathrm{mm})$ & $<3 \mathrm{~m}$ & $<6 \mathrm{~m}$ & $<1 \mathrm{yr}$ & $<4 \mathrm{yr}$ \\
\hline$<1 \mathrm{~m}$ & $\mathrm{NS}$ & 0.043 & 0.05 & 0.0001 \\
$<3 \mathrm{~m}$ & $\mathrm{X}$ & $\mathrm{NS}$ & $\mathrm{NS}$ & 0.015 \\
$<6 \mathrm{~m}$ & & $\mathrm{X}$ & $\mathrm{NS}$ & $\mathrm{NS}$ \\
\hline$<1 \mathrm{yr}$ & & & $\mathrm{X}$ & $\mathrm{NS}$ \\
\hline Depth $(\mathrm{mm})$ & $<3 \mathrm{~m}$ & $<6 \mathrm{~m}$ & $<1 \mathrm{yr}$ & $<4 \mathrm{yr}$ \\
\hline$<1 \mathrm{~m}$ & $\mathrm{NS}$ & $\mathrm{NS}$ & 0.005 & 0.003 \\
\hline$<3 \mathrm{~m}$ & $\mathrm{X}$ & $\mathrm{NS}$ & $\mathrm{NS}$ & 0.036 \\
\hline$<6 \mathrm{~m}$ & & $\mathrm{X}$ & 0.031 & 0.019 \\
\hline$<1 \mathrm{yr}$ & & & $\mathrm{X}$ & $\mathrm{NS}$ \\
\hline Length $(\mathrm{mm})$ & $<3 \mathrm{~m}$ & $<6 \mathrm{~m}$ & $<1 \mathrm{yr}$ & $<4 \mathrm{yr}$ \\
\hline$<1 \mathrm{~m}$ & 0.0001 & 0.0001 & 0.0001 & 0.0001 \\
\hline$<3 \mathrm{~m}$ & $\mathrm{X}$ & $\mathrm{NS}$ & 0.0001 & 0.0001 \\
\hline$<6 \mathrm{~m}$ & & $\mathrm{X}$ & 0.0001 & 0.0001 \\
\hline$<1 \mathrm{yr}$ & & & $\mathrm{X}$ & $\mathrm{NS}$ \\
\hline
\end{tabular}

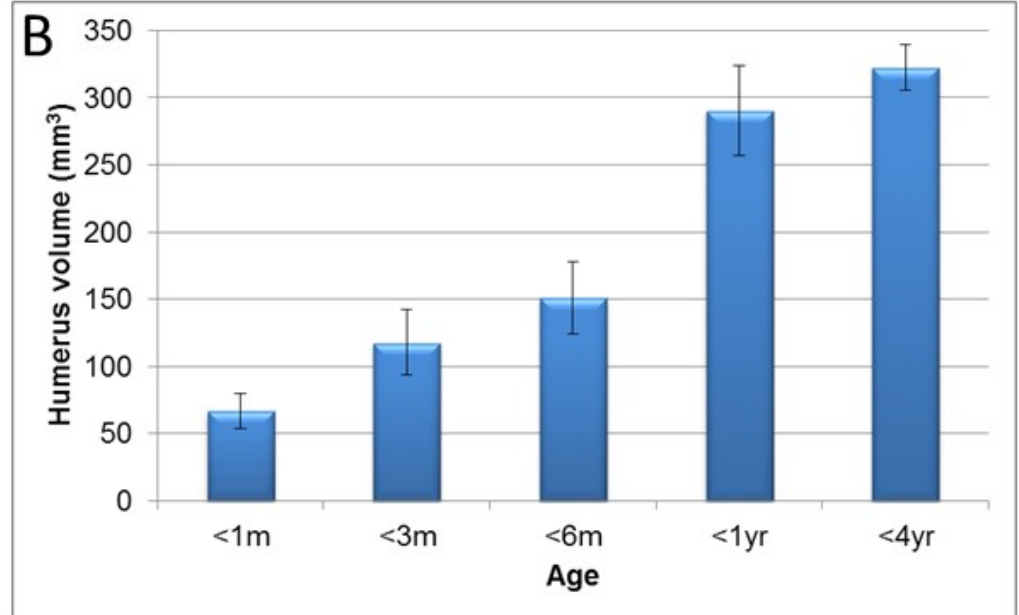

\begin{tabular}{|l|c|c|c|c|}
\hline Volume $\left(\mathrm{mm}^{3}\right)$ & $<3 \mathrm{~m}$ & $<6 \mathrm{~m}$ & $<1 \mathrm{yr}$ & $<4 \mathrm{yr}$ \\
\hline$<1 \mathrm{~m}$ & $\mathrm{NS}$ & 0.005 & 0.0001 & 0.0001 \\
\hline$<3 \mathrm{~m}$ & $\mathrm{X}$ & NS & 0.0001 & 0.0001 \\
\hline$<6 \mathrm{~m}$ & & $X$ & 0.0001 & 0.0001 \\
\hline$<1 \mathrm{yr}$ & & & $X$ & NS \\
\hline
\end{tabular}

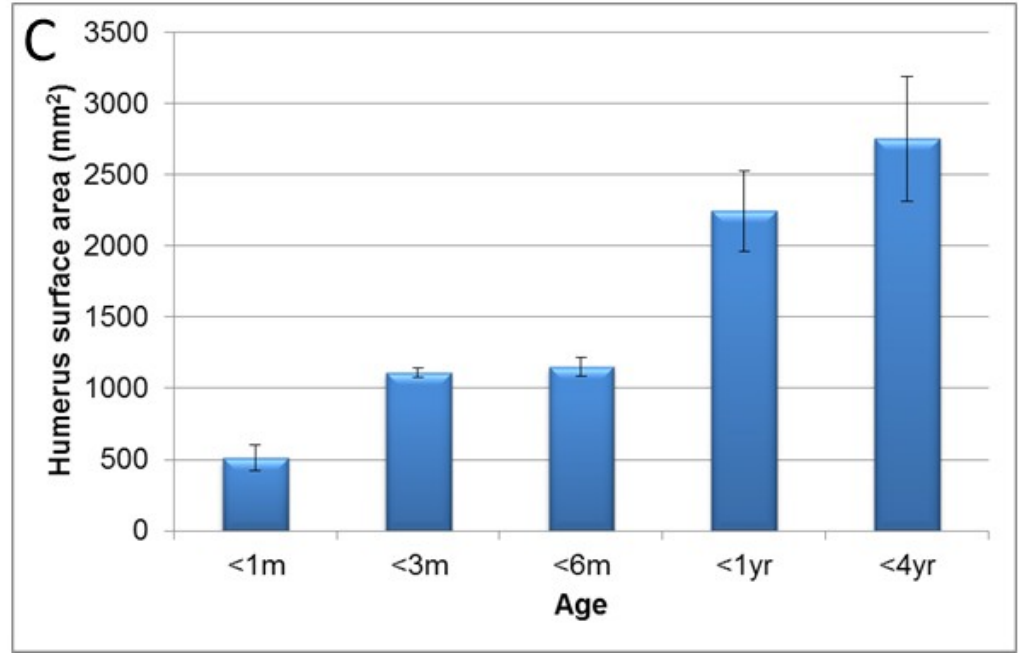

\begin{tabular}{|l|c|c|c|c|}
\hline $\mathrm{SA}\left(\mathrm{mm}^{2}\right)$ & $<3 \mathrm{~m}$ & $<6 \mathrm{~m}$ & $<1 \mathrm{yr}$ & $<4 \mathrm{yr}$ \\
\hline$<1 \mathrm{~m}$ & 0.015 & 0.005 & 0.0001 & 0.0001 \\
\hline$<\mathrm{m}$ & $X$ & NS & 0.0001 & 0.0001 \\
\hline$<6 \mathrm{~m}$ & & $X$ & 0.0001 & 0.0001 \\
\hline$<1 \mathrm{yr}$ & & & $X$ & NS \\
\hline
\end{tabular}




\section{Figure 5}

Figure 5 Micro-CT femur measurements.

Measurements of guinea pig femur aged 0-1 month $(<1 \mathrm{~m}), 1-3$ months $(<3 \mathrm{~m}), 3-6$ months $(<6 \mathrm{~m}), 6$ months-1 year ( $<1 \mathrm{yr})$ and 1-4 years ( $<4 \mathrm{yr}) . A)$ bone width, depth and length, $B)$ surface area and $C$ ) volume with associated ANOVA with post-hoc $P$ value tables. NS=not significant. Mean \pm standard error of the mean error bars. $S A=$ surface area. 
PeerJ Reviewing Manuscript

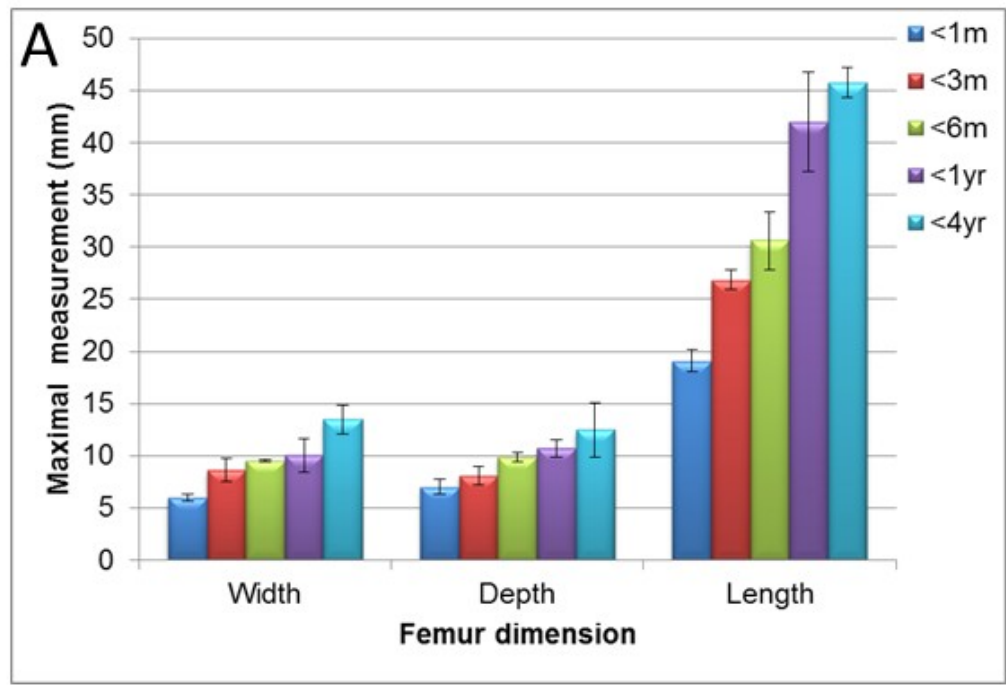

\begin{tabular}{|c|c|c|c|c|}
\hline Width (mm) & $<3 \mathrm{~m}$ & $<6 \mathrm{~m}$ & $<1 y r$ & $<4 y r$ \\
\hline$<1 \mathrm{~m}$ & 0.014 & 0.001 & 0.001 & 0.0001 \\
\hline$<3 m$ & X & NS & NS & 0.0001 \\
\hline$<6 m$ & & $x$ & NS & 0.0001 \\
\hline$<1 \mathrm{yr}$ & & & $\mathrm{x}$ & 0.002 \\
\hline Depth (mm) & $<3 m$ & $<6 \mathrm{~m}$ & $<1 \mathrm{yr}$ & $<4 y r$ \\
\hline$<1 \mathrm{~m}$ & NS & 0.024 & 0.012 & 0.0001 \\
\hline$<3 m$ & $\mathrm{x}$ & NS & NS & 0.004 \\
\hline$<6 m$ & & $\mathrm{x}$ & NS & 0.046 \\
\hline$<1 \mathrm{yr}$ & & & $x$ & NS \\
\hline Length (mm) & $<3 m$ & $<6 m$ & $<1 \mathrm{yr}$ & $<4 y r$ \\
\hline$<1 \mathrm{~m}$ & 0.001 & 0.0001 & 0.0001 & 0.0001 \\
\hline$<3 m$ & $x$ & NS & 0.0001 & 0.0001 \\
\hline$<6 m$ & & $\mathrm{X}$ & 0.0001 & 0.0001 \\
\hline$<1 \mathrm{yr}$ & & & $\mathrm{X}$ & NS \\
\hline
\end{tabular}

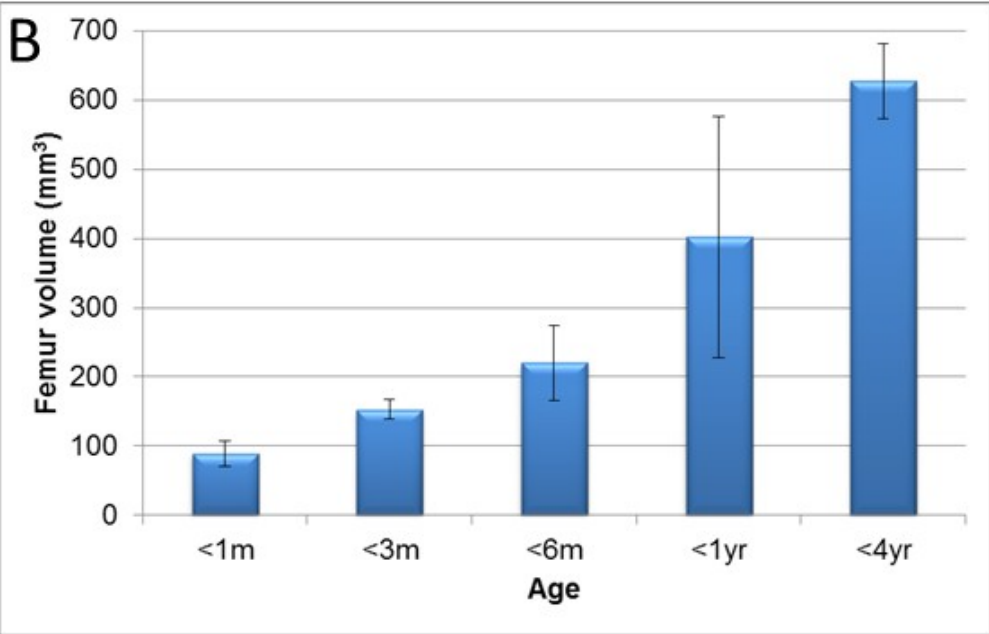

\begin{tabular}{|c|c|c|c|c|}
\hline Volume $\left(\mathrm{mm}^{3}\right)$ & $<3 m$ & $<6 m$ & $<1 \mathrm{yr}$ & $<4 \mathrm{yr}$ \\
\hline$<1 \mathrm{~m}$ & NS & 0.034 & 0.0001 & 0.0001 \\
\hline$<3 m$ & $x$ & NS & 0.001 & 0.0001 \\
\hline$<6 m$ & & $X$ & 0.006 & 0.0001 \\
\hline$<1 y r$ & & & $\mathrm{X}$ & 0.004 \\
\hline
\end{tabular}

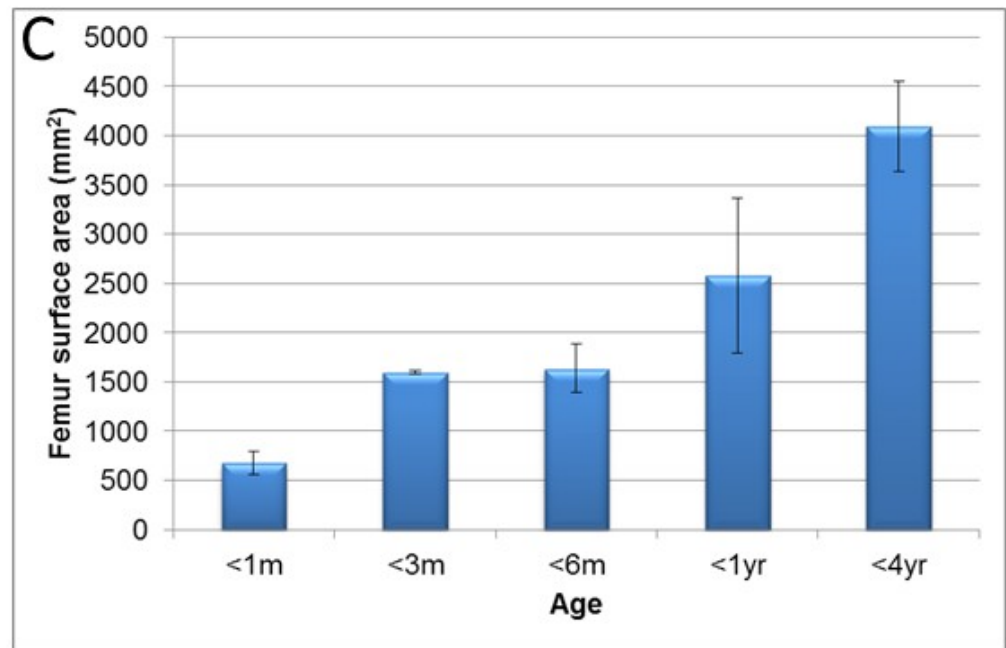

\begin{tabular}{|c|c|c|c|c|}
\hline $\mathrm{SA}\left(\mathrm{mm}^{2}\right)$ & $<3 m$ & $<6 m$ & $<1 \mathrm{yr}$ & $<4 y r$ \\
\hline$<1 \mathrm{~m}$ & \multicolumn{2}{|c|}{0.0050 .004} & 0.0001 & 0.0001 \\
\hline$<3 m$ & \multirow[t]{3}{*}{$x$} & NS & 0.012 & 0.0001 \\
\hline$<6 m$ & & $\mathrm{x}$ & 0.007 & 0.0001 \\
\hline$<1 y r$ & & & $x$ & 0.0001 \\
\hline
\end{tabular}




\section{Figure 6}

Figure 6 Micro-CT bone local thickness heat mapping reconstructions.

Representative heat mapping reconstructions of guinea pig bone localised thickness aged 01 month $(<1 \mathrm{~m})$, 3-6 months $(<6 \mathrm{~m})$ and $1-4$ years $(<4 \mathrm{yr})$. From left to right: Scapula - anterior and posterior, humerus - anterior and posterior and femur - anterior and posterior. Scale bars for each age represent $8 \mathrm{~mm}$.

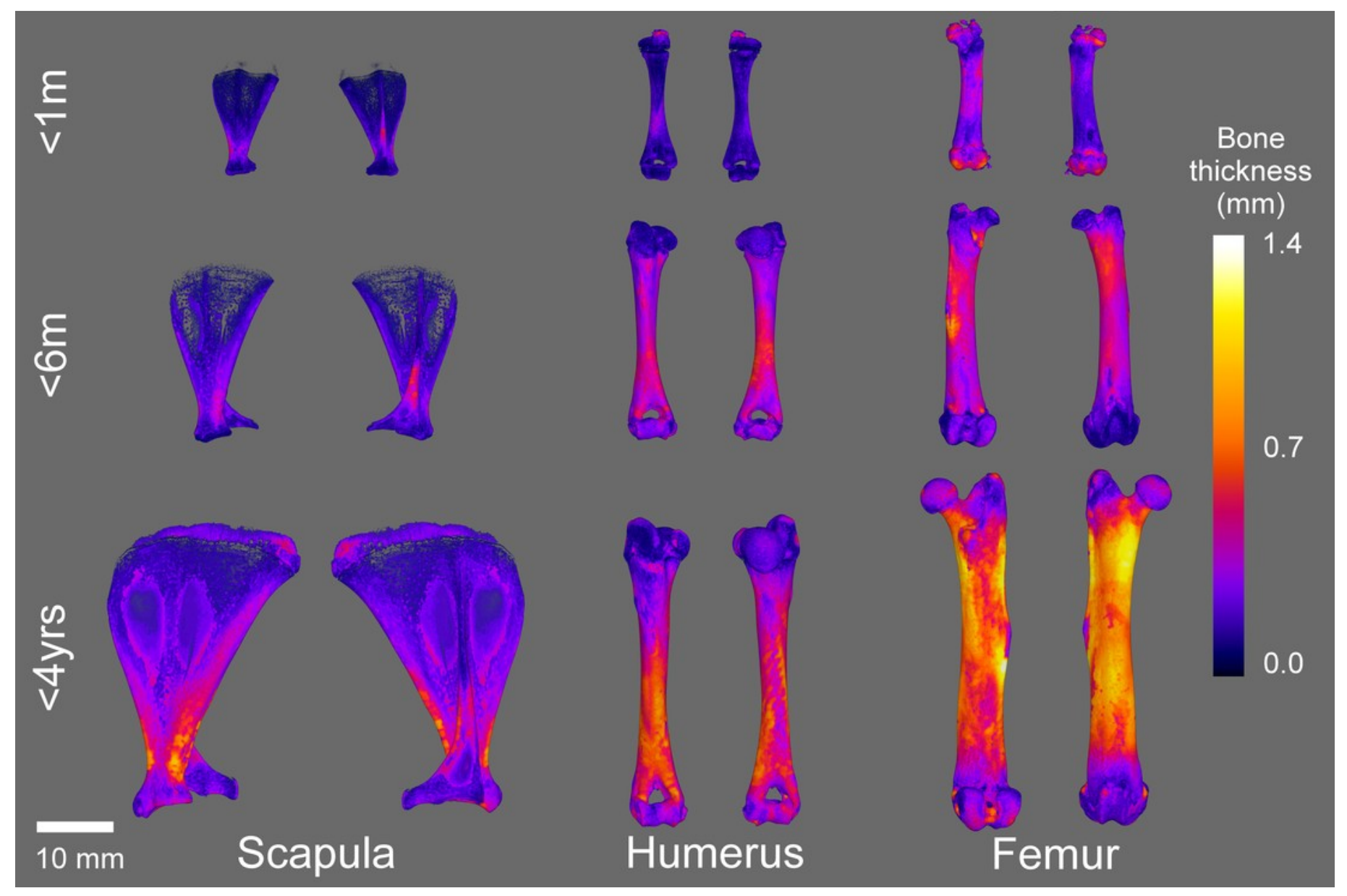




\section{Figure 7}

Figure 7 Micro-CT bone local thickness measurements.

Measurements of guinea pig bone local thickness aged 0-1 month $(<1 \mathrm{~m}), 1-3$ months $(<3 \mathrm{~m})$, 3-6 months $(<6 \mathrm{~m}), 6$ months-1 year ( $<1 \mathrm{yr})$ and $1-4$ years $(<4 \mathrm{yr})$. A) scapula, B) humerus and C) femur with associated ANOVA with post-hoc $P$ value tables. NS=not significant. Mean \pm standard error of the mean error bars. 
PeerJ Reviewing Manuscript

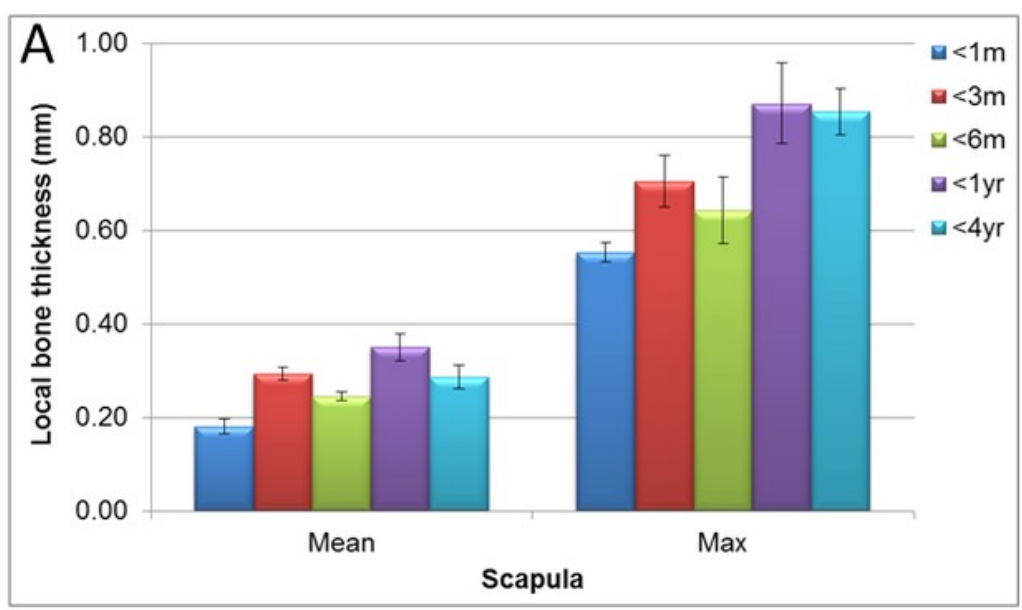

\begin{tabular}{|l|c|c|c|c|}
\hline Mean $(\mathrm{mm})$ & $<3 \mathrm{~m}$ & $<6 \mathrm{~m}$ & $<1 \mathrm{yr}$ & $<4 \mathrm{yr}$ \\
\hline$<1 \mathrm{~m}$ & 0.003 & 0.028 & 0.0001 & 0.0001 \\
\hline$<3 \mathrm{~m}$ & $\mathrm{X}$ & $\mathrm{NS}$ & $\mathrm{NS}$ & $\mathrm{NS}$ \\
\hline$<6 \mathrm{~m}$ & & $\mathrm{X}$ & 0.003 & $\mathrm{NS}$ \\
\hline$<1 \mathrm{yr}$ & & & $X$ & 0.022 \\
\hline \hline $\operatorname{Max}(\mathrm{mm})$ & $<3 \mathrm{~m}$ & $<6 \mathrm{~m}$ & $<1 \mathrm{yr}$ & $<4 \mathrm{yr}$ \\
\hline$<1 \mathrm{~m}$ & 0.042 & $\mathrm{NS}$ & 0.0001 & 0.0001 \\
\hline$<3 \mathrm{~m}$ & $\mathrm{X}$ & $\mathrm{NS}$ & 0.0001 & 0.0001 \\
\hline $6 \mathrm{~m}$ & & $\mathrm{X}$ & 0.005 & 0.005 \\
\hline $1 \mathrm{yr}$ & & & $X$ & $\mathrm{NS}$ \\
\hline
\end{tabular}

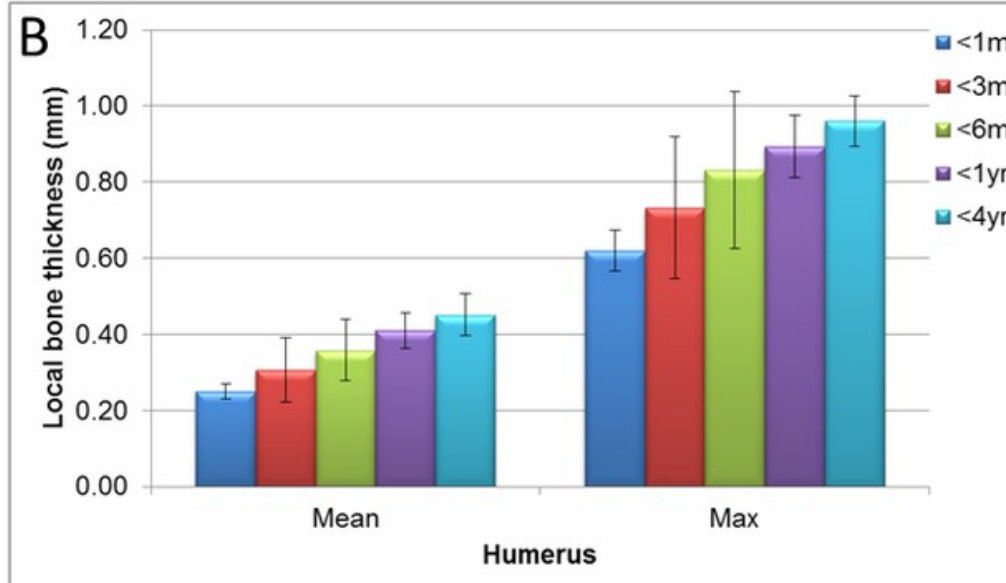

\begin{tabular}{|c|c|c|c|c|}
\hline Mean $(\mathrm{mm})$ & $<3 \mathrm{~m}$ & $<6 \mathrm{~m}$ & $<1 y r$ & $<4 \mathrm{yr}$ \\
\hline$<1 \mathrm{~m}$ & NS & NS & 0.002 & 0.0001 \\
\hline$<3 m$ & $x$ & NS & NS & 0.014 \\
\hline$<6 \mathrm{~m}$ & & $x$ & NS & 0.023 \\
\hline$<1 y r$ & & & $x$ & NS \\
\hline $\operatorname{Max}(\mathrm{mm})$ & $<3 m$ & $<6 \mathrm{~m}$ & $<1 y r$ & $<4 y r$ \\
\hline$<1 \mathrm{~m}$ & NS & NS & 0.011 & 0.002 \\
\hline$<3 m$ & $\mathrm{x}$ & NS & NS & NS \\
\hline$<6 \mathrm{~m}$ & & $x$ & NS & NS \\
\hline$<1 \mathrm{yr}$ & & & $x$ & NS \\
\hline
\end{tabular}

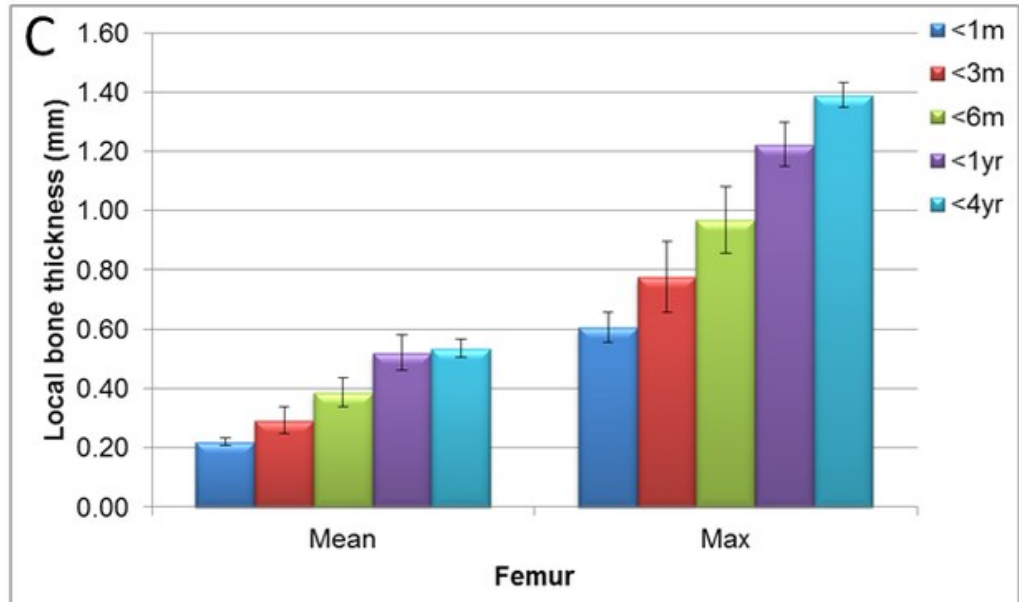

\begin{tabular}{|l|cccc|}
\hline Mean $(\mathrm{mm})$ & $<3 \mathrm{~m}$ & $<6 \mathrm{~m}$ & $<1 \mathrm{yr}$ & $<4 \mathrm{yr}$ \\
\hline$<1 \mathrm{~m}$ & $\mathrm{NS}$ & 0.0001 & 0.0001 & 0.0001 \\
\hline$<3 \mathrm{~m}$ & $\mathrm{X}$ & 0.015 & 0.0001 & 0.0001 \\
\hline$<6 \mathrm{~m}$ & & $\mathrm{X}$ & 0.02 & 0.012 \\
\hline$<1 \mathrm{yr}$ & & & $\mathrm{X}$ & $\mathrm{NS}$ \\
\hline \hline $\operatorname{Max}(\mathrm{mm})$ & $<3 \mathrm{~m}$ & $<6 \mathrm{~m}$ & $<1 \mathrm{yr}$ & $<4 \mathrm{yr}$ \\
\hline$<1 \mathrm{~m}$ & $\mathrm{NS}$ & 0.0001 & 0.0001 & 0.0001 \\
\hline$<3 \mathrm{~m}$ & $\mathrm{X}$ & 0.033 & 0.0001 & 0.0001 \\
\hline$<\mathrm{m}$ & & $X$ & $\mathrm{NS}$ & 0.002 \\
\hline$<1 \mathrm{yr}$ & & & $X$ & $\mathrm{NS}$ \\
\hline
\end{tabular}




\section{Figure 8}

Figure 8 Bone growth and localised thickness throughout development.

Percentage bone growth $(A)$ and local thickness $(B)$ of $0-1$ month $(<1 \mathrm{~m}), 1-3$ months $(<3 \mathrm{~m})$, 3-6 months $(<6 \mathrm{~m}), 6$ months-1 year $(<1 \mathrm{yr})$ old guinea pigs in comparison to $1-4$ year olds. 
PeerJ Reviewing Manuscript
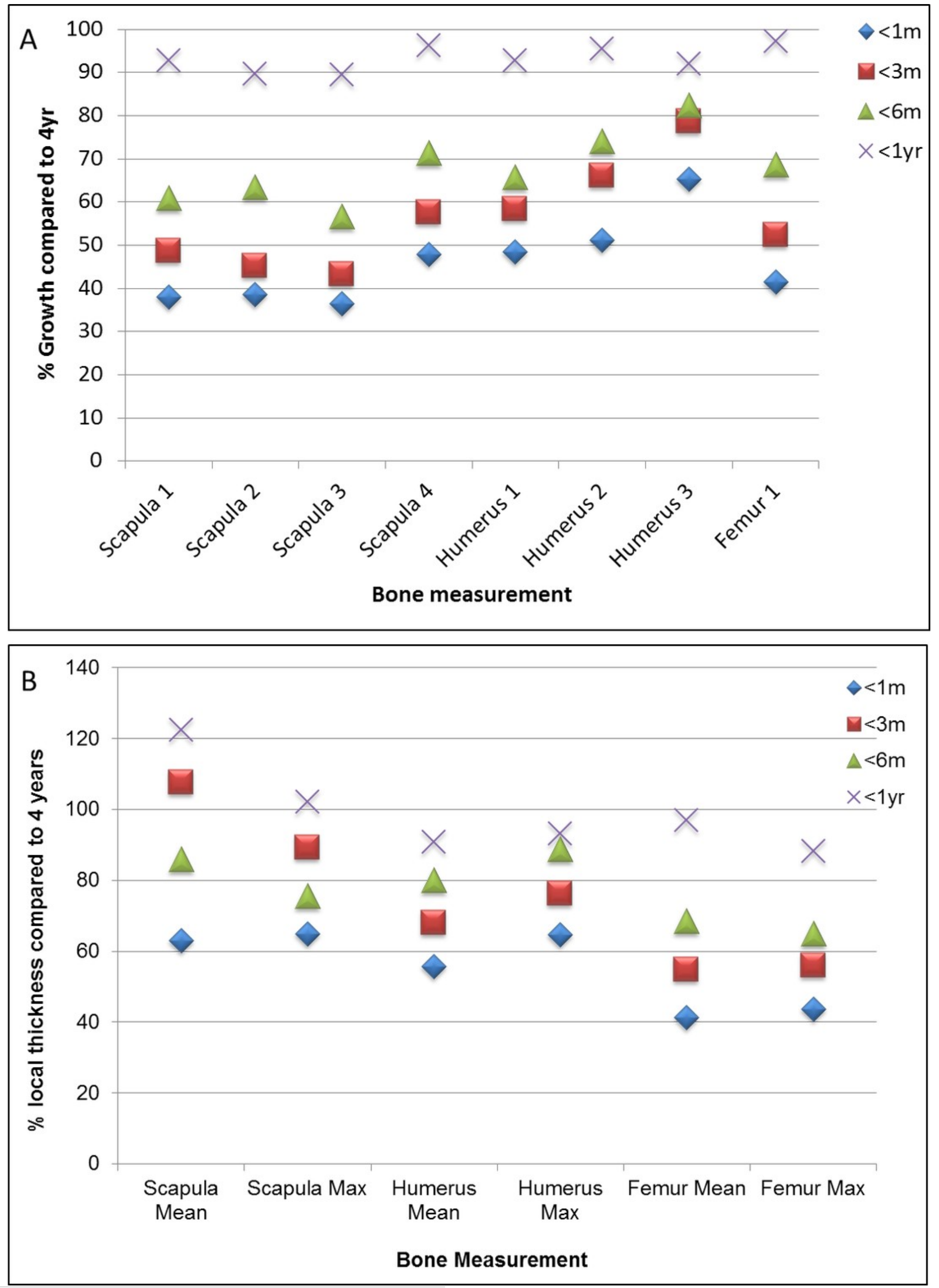


\section{Figure 9}

Figure 9 Gross anatomical features of the humerus.

Humerus anterior (top row) and posterior (lower row) views showing examples of the supratrochlear foramen (as indicated by closed arrowhead) at 0-1 month $(<1 \mathrm{~m}), 1-3$ months $(<3 \mathrm{~m})$, 3-6 months $(<6 \mathrm{~m}), 6$ months-1 year ( $<1 \mathrm{yr})$ and 1 year-4 years $(<4 \mathrm{yr})$. Examples of nutrient foramina in a 4 year old humerus are indicated (open arrowhead). Scale bars represent $8 \mathrm{~mm}$. 


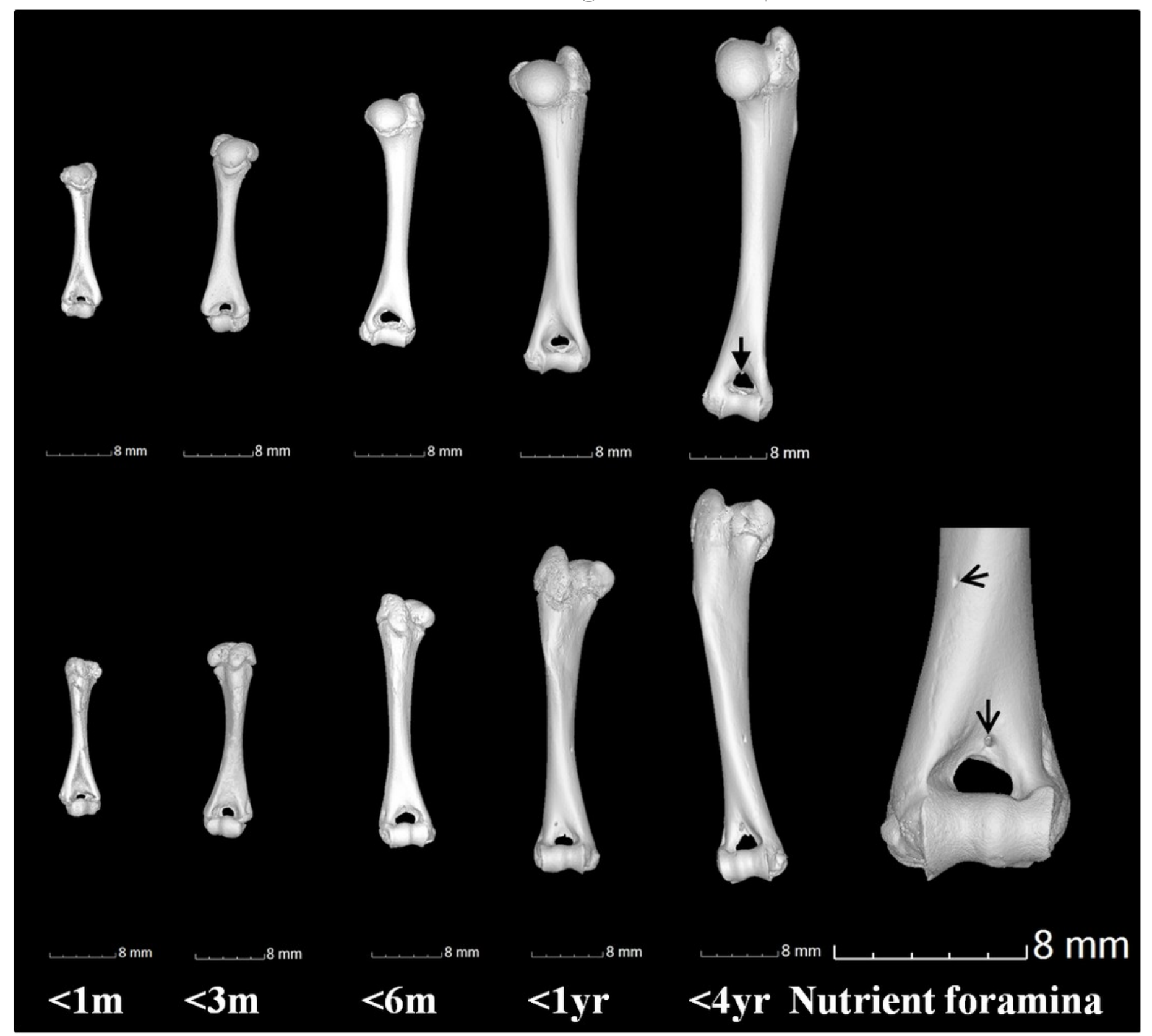

